\title{
Membrane Interactions of Virus-like Mesoporous Silica Nanoparticles
}

Sara Malekkhaiat Häffner, Elisa Parra-Ortiz,* Kathryn L. Browning, Elin Jørgensen, Maximilian W. A. Skoda, Costanza Montis, Xiaomin Li, Debora Berti, Dongyuan Zhao, and Martin Malmsten
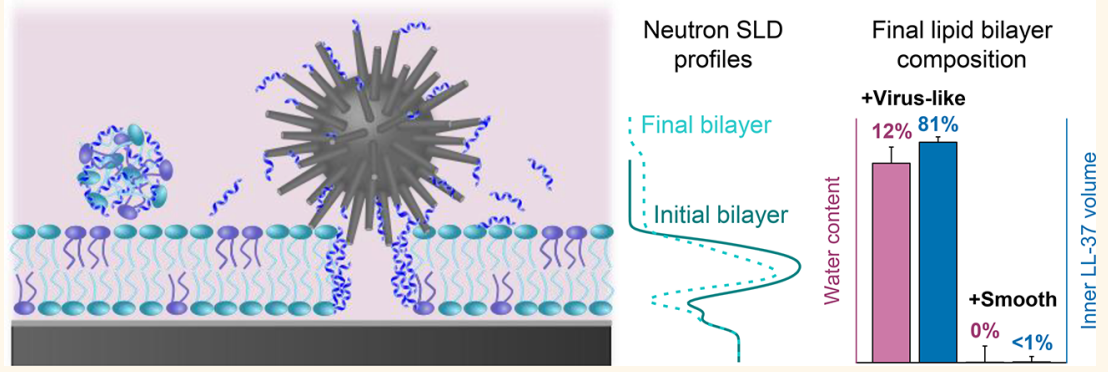

ABSTRACT: In the present study, we investigated lipid membrane interactions of silica nanoparticles as carriers for the antimicrobial peptide LL-37 (LLGDFFRKSKEKIGKEFKRIVQRIKDFLRNLVPRTES). In doing so, smooth mesoporous nanoparticles were compared to virus-like mesoporous nanoparticles, characterized by a "spiky" external surface, as well as to nonporous silica nanoparticles. For this, we employed a combination of neutron reflectometry, ellipsometry, dynamic light scattering, and $\zeta$-potential measurements for studies of bacteriamimicking bilayers formed by palmitoyloleoylphosphatidylcholine/palmitoyloleoylphosphatidylglycerol. The results show that nanoparticle topography strongly influences membrane binding and destabilization. We found that viruslike particles are able to destabilize such lipid membranes, whereas the corresponding smooth silica nanoparticles are not. This effect of particle spikes becomes further accentuated after loading of such particles with LL-37. Thus, peptide-loaded virus-like nanoparticles displayed more pronounced membrane disruption than either peptideloaded smooth nanoparticles or free LL-37. The structural basis of this was clarified by neutron reflectometry, demonstrating that the virus-like nanoparticles induce trans-membrane defects and promote incorporation of LL-37 throughout both bilayer leaflets. The relevance of such effects of particle spikes for bacterial membrane rupture was further demonstrated by confocal microscopy and live/dead assays on Escherichia coli bacteria. Taken together, these findings demonstrate that topography influences the interaction of nanoparticles with bacteria-mimicking lipid bilayers, both in the absence and presence of antimicrobial peptides, as well as with bacteria. The results also identify virus-like mesoporous nanoparticles as being of interest in the design of nanoparticles as delivery systems for antimicrobial peptides.

KEYWORDS: inorganic nanoparticles, antimicrobial peptides, membrane disruption, bacteria killing, nanoparticle topography, spiky structure

$\mathrm{T}$ he increase in antibiotic resistance among bacteria ${ }^{1}$ has spawned a need for additional therapeutics to combat infection. One class of compounds attracting current interest in relation to this is antimicrobial peptides (AMPs), which may be designed to display potent antimicrobial effects, as well as anti-inflammatory and other host defense properties. $^{2,3}$ Several mechanisms contribute to such effects, but interactions with bacterial membrane components and resulting membrane destabilization play critical roles. Ap- proaches employed for reaching selective destabilization of bacterial membranes include, for example, directed screening, ${ }^{4}$

Received: December 11, 2020

Accepted: March 10, 2021 

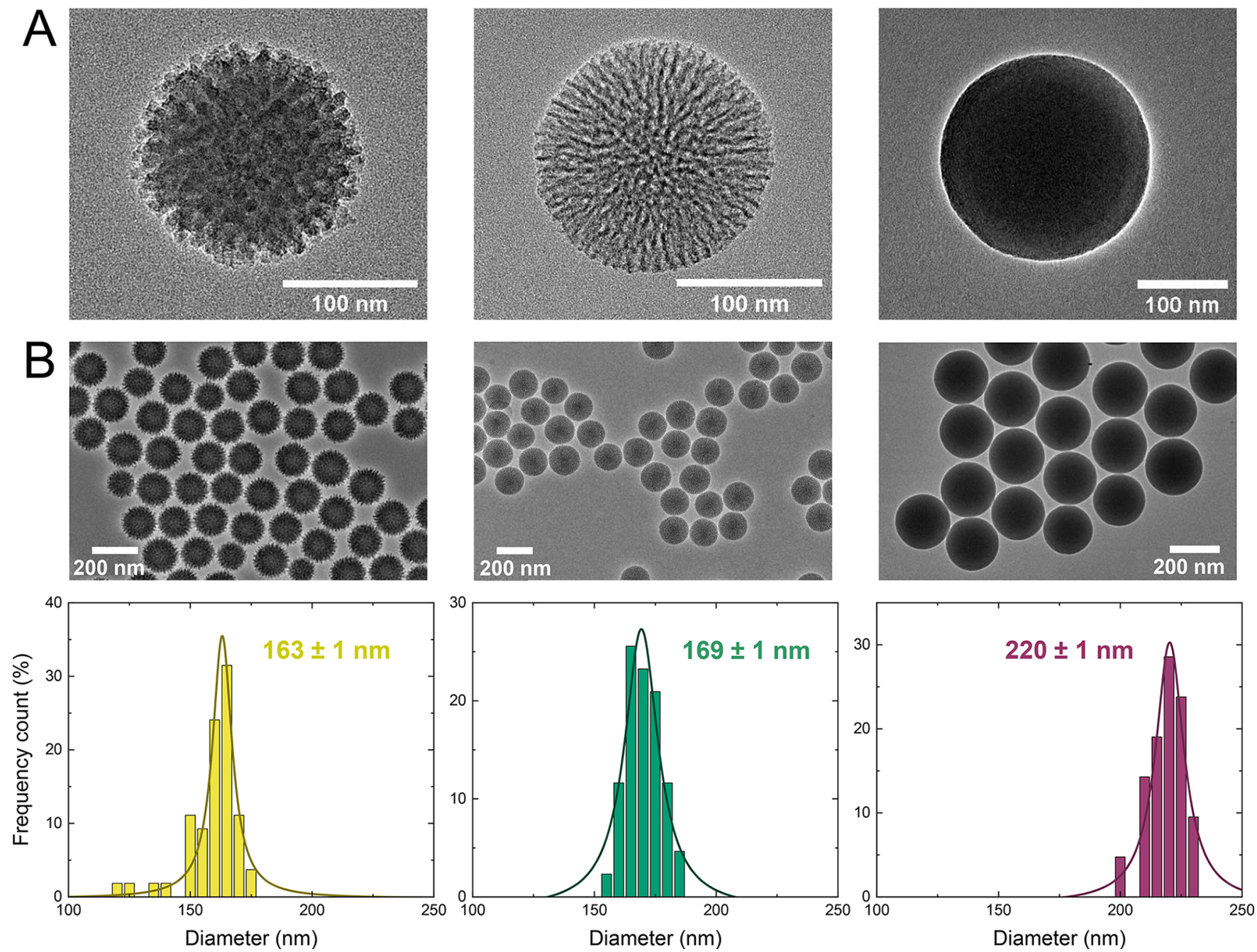

Figure 1. (A) Detailed TEM images of virus-like mesoporous (left), smooth mesoporous (middle), and smooth nonporous (right) nanoparticles. (B) TEM images of a large number of nanoparticles (top), together with histograms (bottom) over particle sizes obtained for the three nanoparticles types. Lorentzian fits of these distributions were performed, from which the resulting average sizes and standard errors are shown.

end-tagging, ${ }^{5}$ and mimicry of peptides from endogenous proteins with antimicrobial properties. ${ }^{6}$ On the basis of these and other approaches, AMPs can be designed for selective potency in combatting infection and inflammation. Contrasting the considerable efforts placed on peptide identification, however, much less focus has been placed on AMP delivery systems, despite AMPs being challenging compounds from a drug delivery perspective due to their relatively large size, net positive charge, amphiphilicity, and susceptibility to proteolytic degradation.

Complementing more established delivery systems based on polymers, surfactants, and (polar) lipids, a wide range of inorganic nanoparticles has attracted increasing interest as delivery systems for bio-macromolecular drugs, such as peptides, proteins, siRNA, and DNA. ${ }^{8}$ Such materials may also display antimicrobial effects on their own, which may be triggered by various parameters. ${ }^{9,10}$ Antimicrobial effects of inorganic nanomaterials have been suggested to involve direct membrane destabilization ${ }^{11,12}$ and oxidative degradation of bacterial membrane lipids and/or proteins by reactive oxygen species generated under illumination, ${ }^{13,14}$ as well as membrane disruption and/or protein denaturation on localized heating induced by either magnetic fields ${ }^{15,16}$ or light. ${ }^{17,18}$ Thus, while antimicrobial effects have been increasingly demonstrated for a range of inorganic nanomaterials during the past few years, the mechanism behind such effects remains unclear, notably in relation to the interaction between such nanomaterials and bacterial membrane components, particularly phospholipids and lipopolysaccharides. Furthermore, as selectivity between bacteria and human cells remains a concern for a range of nanomaterials, their combination with compounds for effectively "targeting" such nanomaterials to bacteria and infected tissue has attracted recent interest. ${ }^{19}$ Here, AMPs offer interesting opportunities, as these can be designed to display pronounced selectivity, with potent antimicrobial effects also against challenging pathogens (such as strains resistant to various antibiotics), but still low toxicity against human cells. ${ }^{5}$ Conversely, nanoparticles offer advantages as delivery systems for AMPs, e.g., relating to control of release rate, protection against proteolytic degradation, and suppression of binding to serum proteins, ${ }^{20,21}$ thus prolonging the bloodstream circulation, as well as otherwise increased bioavailability. ${ }^{7}$ For such combined nanoparticle/AMP systems, even less is known with regard to membrane interactions, notably concerning the relative importance of nanoparticles, free peptide, and peptideloaded nanoparticles, how this varies during peptide release, 
A

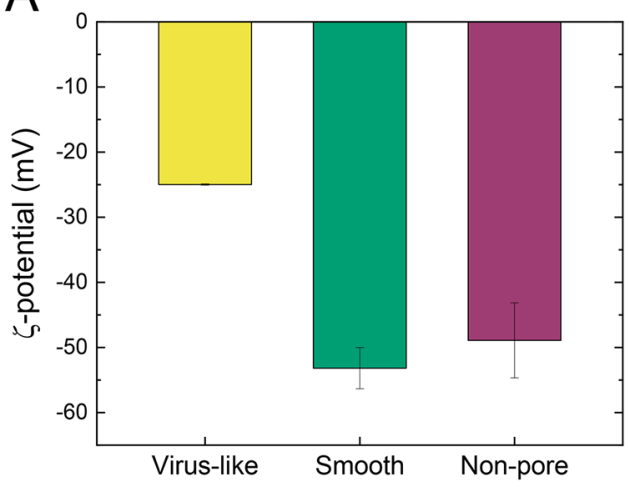

C

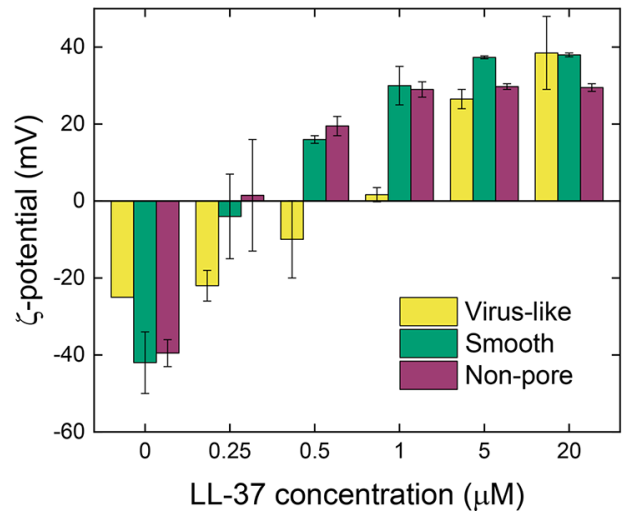

B
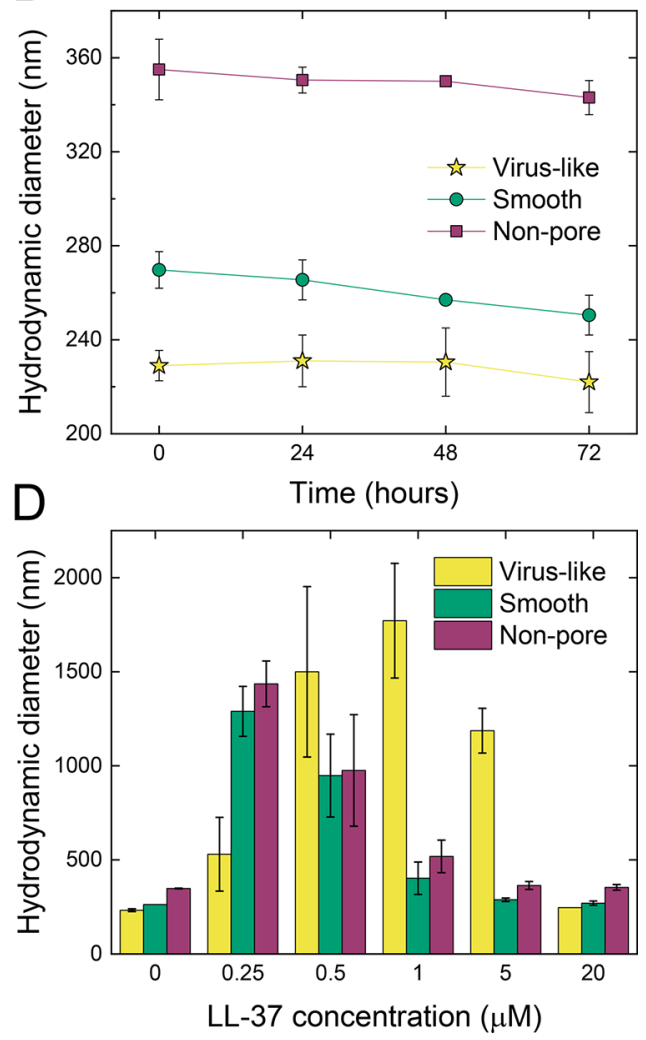

Figure 2. (A) $\zeta$-potential and (B) primary size of the different nanoparticles over time in $10 \mathrm{mM}$ Tris pH 7.4. (C) $\zeta$-potential and (D) effective aggregate size of the three nanoparticles in the presence of LL-37 in $10 \mathrm{mM} \mathrm{pH} 7.4(n=3$, mean \pm SD).

and how membrane interactions translate into antimicrobial effects and cell toxicity. ${ }^{22,23}$

In the present investigation, focus was placed on mesoporous silica nanoparticles. These have well-defined pores in the nanometer range, ${ }^{24}$ making them interesting as carriers of AMPs, since peptide loading and release can be controlled through pore structure and chemistry. ${ }^{25}$ Addressing effects of charge and porosity for such systems, Braun et al. investigated membrane interactions and antimicrobial effects of mesoporous silica nanoparticles combined with the AMP LL37 (LLGDFFRKSKEKIGKEFKRIVQRIKDFLRNL VPRTES). ${ }^{26}$ For negatively charged mesoporous silica nanoparticles, which did not bind to negatively charged dioleoylphosphatidylethanolamine/dioleoylphosphatidylglycerol bilayers on their own, the membrane lysis observed after LL37 loading was demonstrated to rely on released LL-37. In contrast to the mesoporous nanoparticles, LL-37 was localized only at the outer surface for nonporous silica nanoparticles. In addition, due to the higher negative surface charge of the nonporous particles, peptide release was slower and membrane destabilization in that case was caused directly by the peptideloaded particles, rather than by released peptide.

Extending on these previous studies, we here address effects of nanoparticle topography on membrane interactions of mesoporous silica nanoparticles in the absence and presence of LL-37, by comparing smooth (conventional) mesoporous nanoparticles with particles of a spiky or "virus-like" appearance. $^{27}$ Such virus-like particles may have the potential to effectively "puncture" bacterial membranes through mechanical action, similar to macroscopic surfaces with spiky texture, which have previously been found to induce membrane rupture and antimicrobial effects against bacteria under gravitational settling. ${ }^{28}$ In addition, virus-like nanoparticles have been shown to display better uptake into HeLa cells compared to smooth mesoporous nanoparticles. ${ }^{29}$ However, while likely involving membrane interactions, the mechanistic foundation for such observations remains poorly understood. Furthermore, it is not known whether such effects of topography translate into bacterial membrane destabilization by nanoparticles undergoing Brownian motion, or if any effect of nanoparticle topography can be enhanced by AMP loading.

\section{RESULTS AND DISCUSSION}

Addressing such effects of nanoparticle topography, lipid membrane interactions were here compared between virus-like and smooth mesoporous silica nanoparticles, including also smooth nonporous silica nanoparticles as control. These silica nanoparticles were also employed as carriers for the AMP LL37. Lipid membrane interactions of the bare and peptideloaded nanoparticles were observed by employing a battery of experimental methodologies, including neutron reflectometry, ellipsometry, dynamic light scattering (DLS), and $\zeta$-potential measurements for bacteria-mimicking model bilayers formed by palmitoyloleoylphosphatidylcholine/palmitoyloleoylphosphatidylglycerol (POPC/POPG). In addition, the effects of nanoparticle topography and LL-37 loading on bacterial membrane destabilization were investigated by confocal microscopy to connect mechanistic studies in model systems with biological functionality.

Nanoparticle Properties and LL-37 Loading. As a first step, the nanoparticles investigated were characterized. Trans- 
mission electron microscopy (TEM) images showed the viruslike particles to be covered with dense spiky features, on average $15 \mathrm{~nm}$ long and with an average separation of $30 \mathrm{~nm}$ (Figure 1A). In contrast, both the smooth mesoporous and the nonporous silica nanoparticles did not display any such features, but were smooth and spherical. Shown in Figure 1B are a larger number of nanoparticles, together with histograms over particle sizes representing relative frequencies. By performing Lorentzian fits, the resulting average sizes and standard errors of the distributions were found to be $163 \pm 1$, $169 \pm 1$, and $220 \pm 1 \mathrm{~nm}$ for the virus-like mesoporous, the smooth mesoporous, and the nonporous nanoparticles, respectively.

After dispersion in $10 \mathrm{mM}$ Tris, $\mathrm{pH} 7.4$, the nanoparticles were characterized in terms of $\zeta$-potential and hydrodynamic size. The silica nanoparticles displayed a negative $\zeta$-potential of $-25 \pm 1,-53 \pm 3$, and $-50 \pm 6 \mathrm{mV}$, for virus-like, smooth, and nonporous nanoparticles, respectively (Figure 2A). Furthermore, the size of the nanoparticles were found to be colloidally stable for at least $72 \mathrm{~h}$ in $10 \mathrm{mM}$ Tris, $\mathrm{pH} 7.4$ (Figure 2B), with hydrodynamic diameters of $229 \pm 6,270 \pm$ 8 , and $355 \pm 13 \mathrm{~nm}$ for virus-like, smooth, and nonporous nanoparticles, respectively, slightly larger in size compared to the average particle sizes extracted from TEM images. This discrepancy is very likely due to the difference between dry and hydrodynamic the radii of particles, and also due to some limited aggregation and polydispersity. A systematic overestimation of the sizes measured by DLS vs TEM has been previously described for silica nanoparticles, even when the dispersion medium had been carefully chosen to minimize aggregation. $^{30}$

Loading LL-37 onto the nanoparticles resulted in surface charge reversal. For the nonporous and the smooth nanoparticles, charge reversal occurred at around $0.25-0.5 \mu \mathrm{M}$, while higher LL-37 concentrations $(0.5-1 \mu \mathrm{M})$ were needed for reversing the charge of the virus-like nanoparticles, indicating preferential binding of LL-37 at the external surfaces of these nanoparticles. At a peptide concentration of $5 \mu \mathrm{M}$, saturation binding was observed for both the nonporous and the smooth mesoporous nanoparticles, while saturation did not occur until $20 \mu \mathrm{M}$ LL-37 for the virus-like nanoparticles (Figure 2C). This difference in LL-37 loading and resulting effective $\zeta$-potential could be also seen by measuring the particle size after loading with LL-37 as a function of peptide concentration. Thus, an increase in size was obtained on low LL-37 binding for all nanoparticles, mirroring charge neutralization and colloidal destabilization, whereas good dispersibility of the individual particles was observed after charge reversal at high LL-37 concentrations. Mirroring the $\zeta$ potential results, a higher peptide concentration was required for reaching complete redispersion of the virus-like particles than for the two other nanoparticles (Figure 2D).

Membrane Destabilization by Empty and PeptideLoaded Nanoparticles. Liposome leakage experiments were next performed to assess membrane interactions of the nanoparticles in the absence and presence of LL-37 with bacteria-mimicking POPC/POPG bilayers. No signs of largescale aggregation were observed after mixing liposomes and nanoparticles (Supporting Information Figure S1); hence, leakage experiments report on membrane destabilization of largely non-aggregated liposomes. In the absence of LL-37, the virus-like nanoparticles induced leakage in negatively charged $(\zeta=-27 \pm 4 \mathrm{mV})$ liposomes, albeit at relatively high particle concentrations, whereas neither the smooth mesoporous nor the nonporous nanoparticles induced any measurable leakage induction (Figure 3A). For the simultaneous presence of nanoparticles and LL-37, a leakage assay was performed, in which the LL-37 concentration was kept constant at $0.02 \mu \mathrm{M}$ (yielding a liposome leakage of $51 \pm 3 \%$ ) while increasing the nanoparticle concentration. In such a way, the combined effect of peptide binding and membrane destabilization by the mixed LL-37 systems could be elucidated. As can be seen in Figure $3 \mathrm{~B}$, the leakage falls from $50 \%$ in the absence of nanoparticles to approximately $10 \%$ at $0.1 \mathrm{ppm}$ for all three nanoparticles, reflecting that binding of LL-37 to the nanoparticles effectively scavenges the peptide and suppresses its ability to bind to, and destabilize, the liposome membrane. At nanoparticle concentrations above $1 \mathrm{ppm}$, on the other hand, the virus-like nanoparticles cause significantly higher leakage than both the smooth mesoporous and the nonporous nanoparticles, illustrating that the virus-like particles are more efficient in membrane destabilization than the smooth nanoparticles also after peptide loading. A leakage assay was also performed to investigate effects of any residual free LL-37 in solution after loading into the nanoparticles. For this, nanoparticles maximally loaded with LL-37 (reaching peptide loadings of 0.22 and $0.90 \mathrm{~g} / \mathrm{g}$ for the smooth and the virus-like nanoparticles, respectively) were centrifuged down and the supernatant was removed and subsequently added to the liposomes (Figure 3C). The results showed very low leakage, demonstrating that only a low concentration $(<0.002 \mu \mathrm{M})$ of LL-37 remains free in solution after peptide loading to nanoparticle saturation, irrespective of nanoparticle type. Hence, the effects shown above are primarily due to the peptide-loaded nanoparticles.

Moving from liposomes to supported lipid bilayers, ellipsometry experiments were next performed (Figure 4). Mirroring liposome leakage experiments, binding of the bare virus-like nanoparticles to POPC/POPG bilayers was substantially higher $\left(0.180 \pm 0.020 \mathrm{mg} / \mathrm{m}^{2}\right)$ than that of the smooth mesoporous $\left(0.040 \pm 0.001 \mathrm{mg} / \mathrm{m}^{2}\right)$ and the nonporous $\left(0.012 \pm 0.004 \mathrm{mg} / \mathrm{m}^{2}\right)$ nanoparticles (Figure 4A). After LL-37 loading, the virus-like nanoparticles resulted in fast and extensive destabilization of the POPC/POPG bilayer. In contrast, the two smooth peptide-loaded nanoparticles caused a smaller and much more gradual bilayer destabilization process (Figure 4B). Therefore, the more pronounced binding of the bare virus-like particles, as well as the larger effect of the corresponding LL-37-loaded particles in destabilizing supported POPC/POPG bilayers, thus mirror the effects observed in liposome leakage. Due to bilayer destabilization occurring on the same time scale as particle adsorption, it is not possible to unambiguously quantify the maximum particle adsorption at the (disintegrating) bilayers. Despite this, the difference in membrane destabilization observed between empty and LL-37-loaded particles cannot be explained only by electrostatically favorable interactions between the LL-37-loaded nanoparticles and the negatively charged membranes, since the nanoparticles investigated present very similar surface charges upon maximum peptide loading ( +38 and $+39 \mathrm{mV}$ for smooth and virus-like nanoparticles, respectively) (Figure $2 \mathrm{C}$ ). Instead, the pronounced membrane destabilization observed for the peptideloaded virus-like nanoparticles seems to be related to the presence of spiky protrusions. 

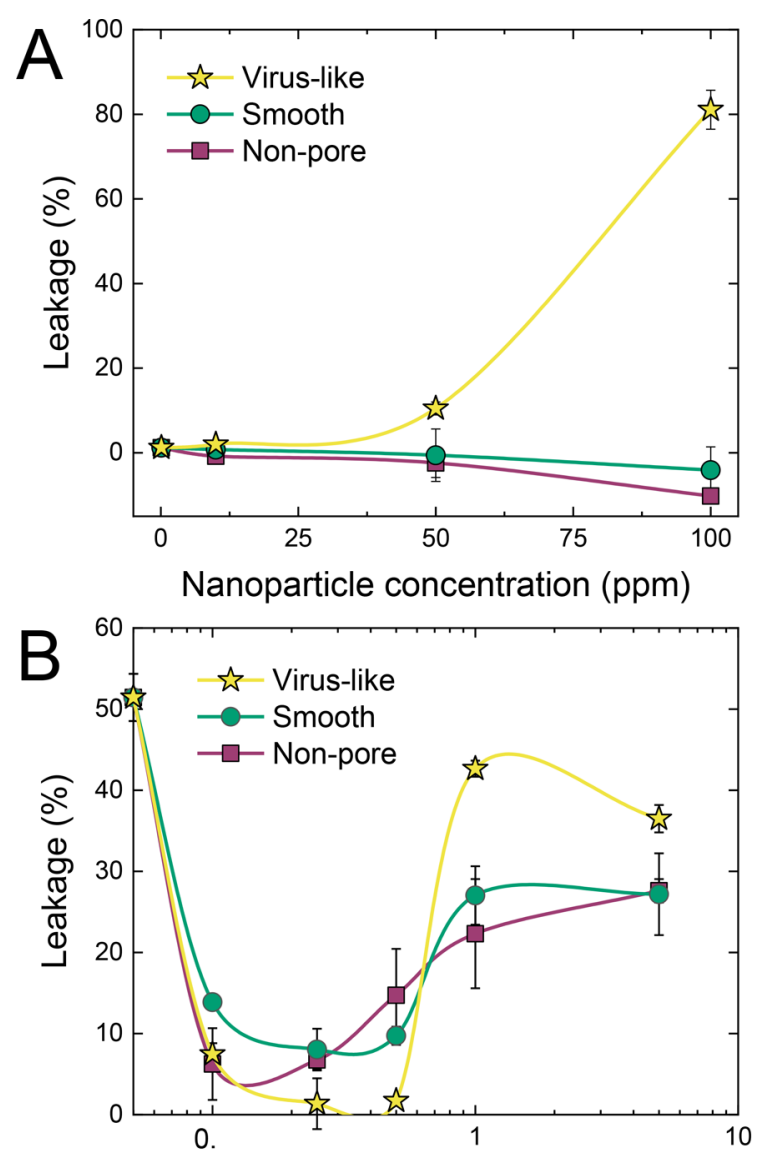

Nanoparticle concentration (ppm)

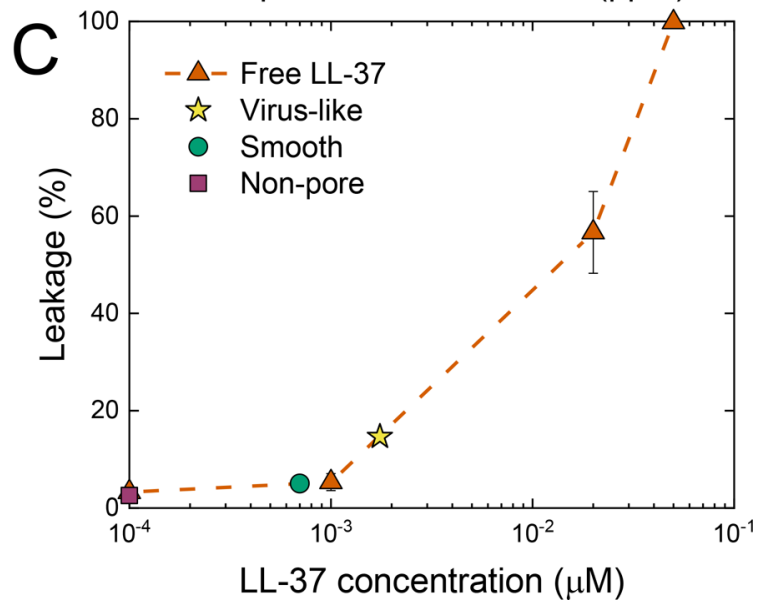

Figure 3. Nanoparticle-induced leakage of POPC/POPG lip-

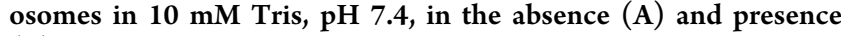
(B) of LL-37. In panel B, the LL-37 concentration was kept constant at $0.02 \mu \mathrm{M}$ while the nanoparticle concentration was varied in peptide-nanoparticle samples premixed prior to liposome exposure. (C) Liposome leakage induced by free LL-37 at varying concentration, as well as by the supernatant obtained after loading the different nanoparticles (10 ppm) with LL-37 to nanoparticle saturation $(0.5 \mu \mathrm{M}$ for smooth and nonporous; $2 \mu \mathrm{M}$ for virus-like nanoparticles, according to Figure $2 \mathrm{C}, \mathrm{D}$, followed by centrifugation to remove the peptide-loaded nanoparticles. As shown in the latter figure, the concentration of free LL-37 after nanoparticle binding was below $0.002 \mu \mathrm{M}$ in all cases $(n=3$, mean $\pm \mathrm{SD})$.

Bilayer Destabilization Mechanisms. The structural features of the supported lipid bilayers were next investigated by neutron reflectivity before and after incubation with viruslike and smooth mesoporous nanoparticles in the absence and presence of LL-37. The structural effects of free LL-37 at the corresponding concentrations were also analyzed for comparison. The supported lipid bilayers were formed by liposome deposition on silicon blocks $(3.5 \pm 0.7 \AA$ surface roughness; $14.0 \pm 0.5 \AA \mathrm{SiO}_{2}$ layer thickness; and $7 \pm 5 \%$ hydration) and characterized in different isotopic contrasts used as buffer media (dTris, hTris, and CMTris). The measured neutron reflectivity curves were analyzed using neutron scattering length density (SLD) data for the different components (Table S1). The fits were performed simultaneously for all contrasts, modeling the bilayers as consisting of three layers (inner and outer headgroups plus one single acyl chain region in the middle), plus a water layer between the $\mathrm{SiO}_{2}$ layer of the silicon substrate and the inner lipid headgroup layer (Model 1 in Figure S2), adding the extra fitting requirement of obtaining the same area per molecule for both the head and the tail regions. ${ }^{31}$ Area per molecule (APM) values were calculated from the molecular volumes of fluid-phase POPC and POPG, obtained from literature data both for the head (331 and 257 $\AA^{3}$, respectively) and the tail regions, $924 \AA^{3} .^{32-34}$ A fixed headgroup thickness of $7.5 \AA$ was assumed for simplicity and for reduction of the number of free parameters in the model, based on previously reported values for negatively charged bilayers. $^{22}$ Full lipid coverage was obtained in all cases, presenting $0 \pm 2 \%$ hydration in the acyl tail region for all of the supported lipid bilayers, and surface coverages of $3.8 \pm 0.2$ $\mathrm{mg} / \mathrm{m}^{2}$. On average, the supported lipid bilayers had an initial head-to-head thickness of $43 \pm 1 \AA$ and an APM of $66 \pm 3 \AA^{2}$ (Table S2), consistent with previously reported values for this system. ${ }^{35,36}$ While asymmetric lipid composition distribution between the bilayer leaflets cannot be completely excluded, fitting of the neutron reflectometry curves for the bilayers could be done assuming absence of such effects. Furthermore, the bilayers formed were all found to have very little defects, both facts arguing against any substantial headgroup asymmetry between the bilayer leaflets.

Only small changes were observed upon addition of $10 \mathrm{ppm}$ of either virus-like or smooth mesoporous nanoparticles, consisting of a slight bilayer thinning $(\sim-1 \pm 1 \AA)$ and a small, $3-5 \%$ increase in APM (Figure S3 and Table S2). Despite these minor changes, the acyl chain hydration was still $0 \pm 2 \%$ in both cases, with no evidence of SLD changes in the different regions, indicating that the overall bilayer integrity was maintained. This is in agreement with liposome leakage results at the same particle concentrations (Figure 3A).

In contrast, on addition of either free LL-37 or LL-37-loaded nanoparticles (the latter loaded to onset saturation based on Figure 2), incubation for $30 \mathrm{~min}$, and final rinse with buffer, significant reflectivity changes were observed, reporting on lipid removal, peptide insertion, and/or structural rearrangements in the bilayers. In all these cases, poor fits were obtained when employing the same model as that for lipid bilayers before addition of peptide and nanoparticles. Therefore, a refined model was employed, consisting of two asymmetric hemilayers, representing the inner (closest to the silicon surface) and outer (closest to the buffer medium) tail regions (Model 2 in Figure S2). In agreement with previous findings, ${ }^{22}$ this model allowed fitting of the data for supported lipid bilayers incubated with free LL-37 (0.5 and $2 \mu \mathrm{M}$ LL-37, Figure S4) and with $10 \mathrm{ppm}$ smooth mesoporous nanoparticles loaded with $0.5 \mu \mathrm{M}$ LL-37 (Figure 5B,D. 
A

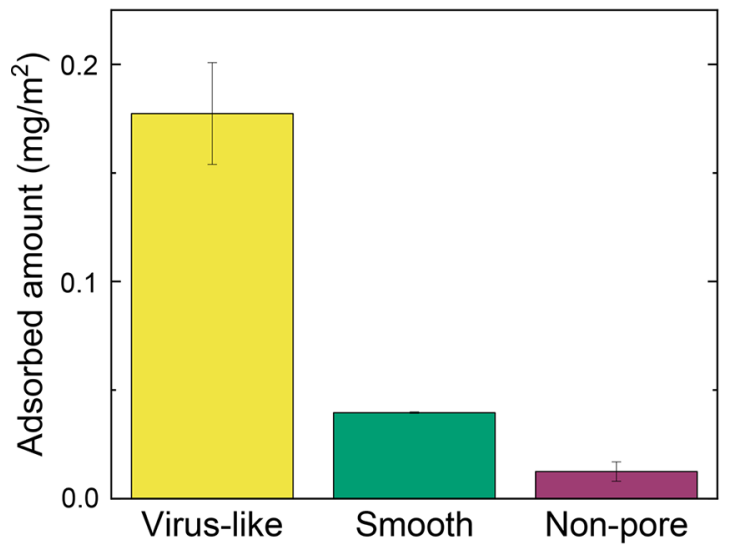

B

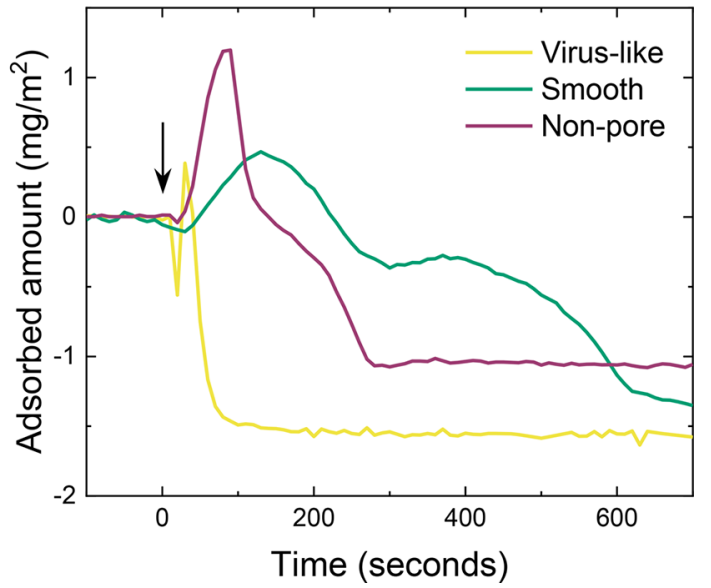

Figure 4. (A) Adsorption of the bare nanoparticles to POPC/POPG supported lipid bilayers in $10 \mathrm{mM}$ Tris, pH 7.4. (B) Kinetics of interaction of LL-37-loaded nanoparticles with supported POPC/POPG bilayers in $10 \mathrm{mM}$ Tris, $\mathrm{pH}$ 7.4, demonstrating faster and more extensive destabilization of the supported POPC/POPG bilayer for the virus-like nanoparticles. The arrow indicates sample addition $(n=2$, mean \pm SD).

A Virus-like + LL-37

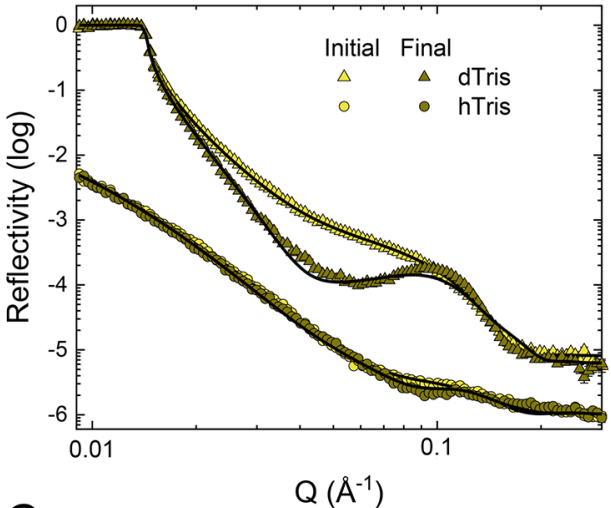

C

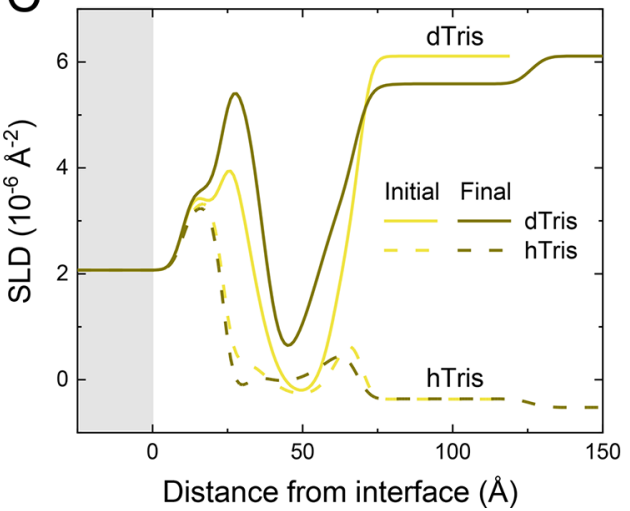

B Smooth + LL-37

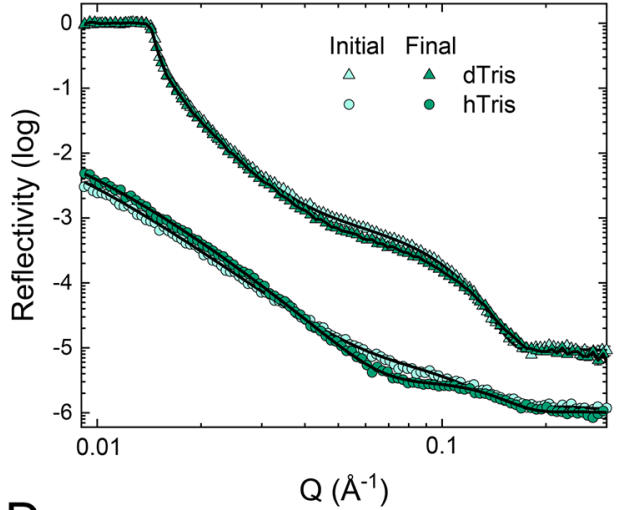

D

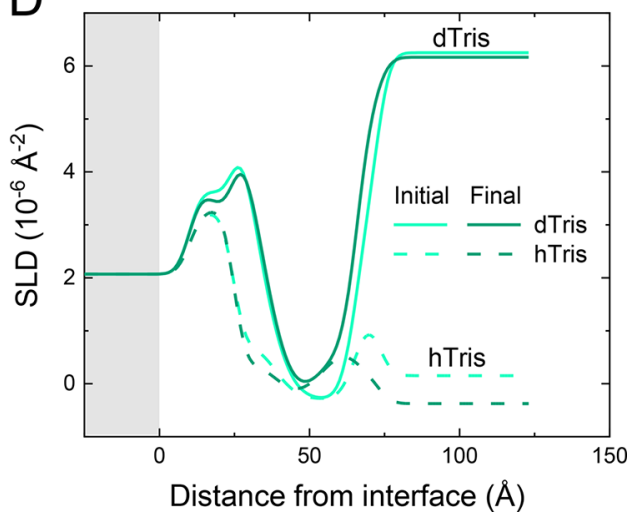

Figure 5. Neutron reflectivity curves with best model fits (A, B), as well as SLD profiles obtained from the fits (C, D) of supported POPC/ POPG bilayers before and after incubation with $10 \mathrm{ppm}$ virus-like (left) and smooth mesoporous nanoparticles (right) loaded with LL-37 to saturation concentrations ( 2 and $0.5 \mu \mathrm{M}$, respectively). Results are shown for two different buffer contrasts, dTris and hTris, and the data for the latter are offset by $10^{-1}$ for clarity. The gray box in the SLD profiles indicates the position of the silicon block and reflecting interface, consisting of bulk $\mathrm{Si}$ and a $\mathrm{SiO}_{2}$ layer.

Differences in the tail region SLD, roughness, and hydration were allowed in the fits, together with increases in inner and outer headgroup hydration, in order to reflect variations due to asymmetrical peptide insertion. Increases were observed in the acyl chain SLD from the original value of $-0.288 \times 10^{-6} \AA^{-2}$ calculated for the $1 / 1$ palmitoyl/oleyl chain mixture (Table
S1), which indicates the incorporation of hydrogenated material, interpreted as the presence of LL-37 (SLD $=2.23$ $\times 10^{-6} \AA^{-2}$ ) in the tail region of the supported lipid bilayers. The relative volume fractions of lipid and LL-37 were quantified from the fitted SLD and hydration values (Table 
S2) by applying a simple proportionality rule to the nonwater fraction of the tail region:

$$
\mathrm{SLD}=\mathrm{vol}_{\text {tails }} \mathrm{SLD}_{\text {tails }}+\text { vol }_{\text {peptide }} \mathrm{SLD}_{\text {peptide }}
$$

As LL-37 and the phosphatidylcholine/phosphatidylglycerol headgroups have very similar SLD values, their relative presence cannot be directly determined from the fits in the same way. Nevertheless, some information on their relative influence can be deduced from observations of hydration differences. The total LL-37 content in the supported lipid bilayer after exposure to $0.5 \mu \mathrm{M}$ LL-37 loaded into the smooth mesoporous nanoparticles was found to be $18 \pm 1$ vol \%. However, peptide insertion was found to be highly asymmetric (Table 1 and Figure 6). The outer headgroup region was

Table 1. Relative Compositions (vol \%) of Lipid, Peptide, and Water Present in the Acyl Chain Regions of Supported POPC/POPG Bilayers after Incubation with Either Free LL-37 or LL-37 Loaded onto 10 ppm Virus-like or Smooth Mesoporous Nanoparticles ${ }^{a}$

\begin{tabular}{|c|c|c|c|c|c|c|c|c|}
\hline & \multicolumn{4}{|c|}{$2 \mu \mathrm{M}$ LL-37 } & \multicolumn{4}{|c|}{$0.5 \mu \mathrm{M}$ LL-37 } \\
\hline & \multicolumn{2}{|c|}{ free } & \multicolumn{2}{|c|}{ virus-like } & \multicolumn{2}{|c|}{ free } & \multicolumn{2}{|c|}{ smooth } \\
\hline & inner & outer & inner & outer & inner & outer & inner & $\overline{\text { outer }}$ \\
\hline lipid & 95 & 43 & 92 & 10 & 100 & 71 & 100 & 52 \\
\hline peptide & $<1$ & 42 & 8 & 33 & 0 & 29 & $<1$ & 48 \\
\hline water & 5 & 15 & $<1$ & 57 & 0 & 0 & 0 & $<1$ \\
\hline
\end{tabular}

${ }^{a}$ Compositions were calculated from differences in SLD and hydration obtained for the inner and outer tail layers. Calculated errors are $\pm 1 \%$.

dramatically affected by peptide/particle insertion, with $93 \pm$ $2 \%$ hydration, whereas neither the inner headgroups nor the tail regions showed any significant increase in hydration $(<1 \%)$. Furthermore, $48 \pm 1 \%$ of the outer tail region volume was occupied by LL-37, while less than 1 vol \% of LL-37 was found in the inner one. As a result of this compositional asymmetry, the outer tail region was much thinner than the inner one $(11 \pm 1 \AA$ vs $20 \pm 1 \AA)$. This is consistent with LL37 inserting only in the outer bilayer leaflet, where it induces defects at the headgroup level, but not membrane-spanning water pores. The effect of free LL-37 at $0.5 \mu \mathrm{M}$ was similar, resulting in a total of $19 \pm 1$ vol \% of LL-37 in the bilayer after exposure. Also in this case, peptide insertion was highly asymmetric, with $29 \pm 2 \mathrm{vol} \%$ in the outer leaflet, $v s 0 \pm 1 \mathrm{vol}$ $\%$ in the inner. Increasing the concentration of free LL-37 to 2 $\mu \mathrm{M}$ resulted in higher peptide insertion in the outer leaflet (42 \pm 1 vol \%), while it remained low $(\sim 0 \pm 1$ vol \%) in the inner leaflet. At this higher LL-37 concentration, the hydration of the acyl chain region was significantly increased to $5 \pm 1 \%$ in the inner and $15 \pm 2 \%$ in the outer leaflet. This indicates higher lipid removal than for the lower peptide concentration and, in the outer layer, replacement of lipid molecules by both water and peptide. This creation of more pronounced defects was accompanied by an overall bilayer thinning to $39 \pm 1 \AA$.

For bilayers incubated with $2 \mu \mathrm{M}$ LL-37 loaded into $10 \mathrm{ppm}$ virus-like nanoparticles (Figure 5A,C), a modified asymmetric layer model including an extra outermost layer (Model 3 in Figure S2) was necessary for good fits, reporting on $58 \pm 4 \AA$ thickness, $4 \pm 1 \AA$ roughness, and $90 \pm 2 \%$ hydration (Tables S2 and S3). The fitted SLD of this layer was $(1.0 \pm 0.1) \times 10^{-6}$ $\AA^{-2}$, i.e., an intermediate value between the SLDs of lipid and LL-37. Assuming (simplistically) that there was no significant incorporation of the nanoparticles within the supported lipid bilayers, this SLD value would correspond to an approximately $50 / 50(\mathrm{v} / \mathrm{v})$ lipid/peptide mixture. Furthermore, significant increases occurred in the hydration of the outer tails (57 \pm $2 \%$ ) and headgroups (52 and $72 \pm 2 \%$ for the outer and inner layers, respectively). This was accompanied by asymmetric LL37 insertion, although less asymmetric than for the free peptide (based on tail SLD values, $8 \pm 3$ vol \% in the inner and $33 \pm 1$ vol \% LL-37 in the outer layers), together with a significant tail region thinning (thicknesses of $5 \pm 2 \AA$ for the outer and $18 \pm$ $1 \AA$ for the inner tail layers) (Figure 6A,B). A significant total
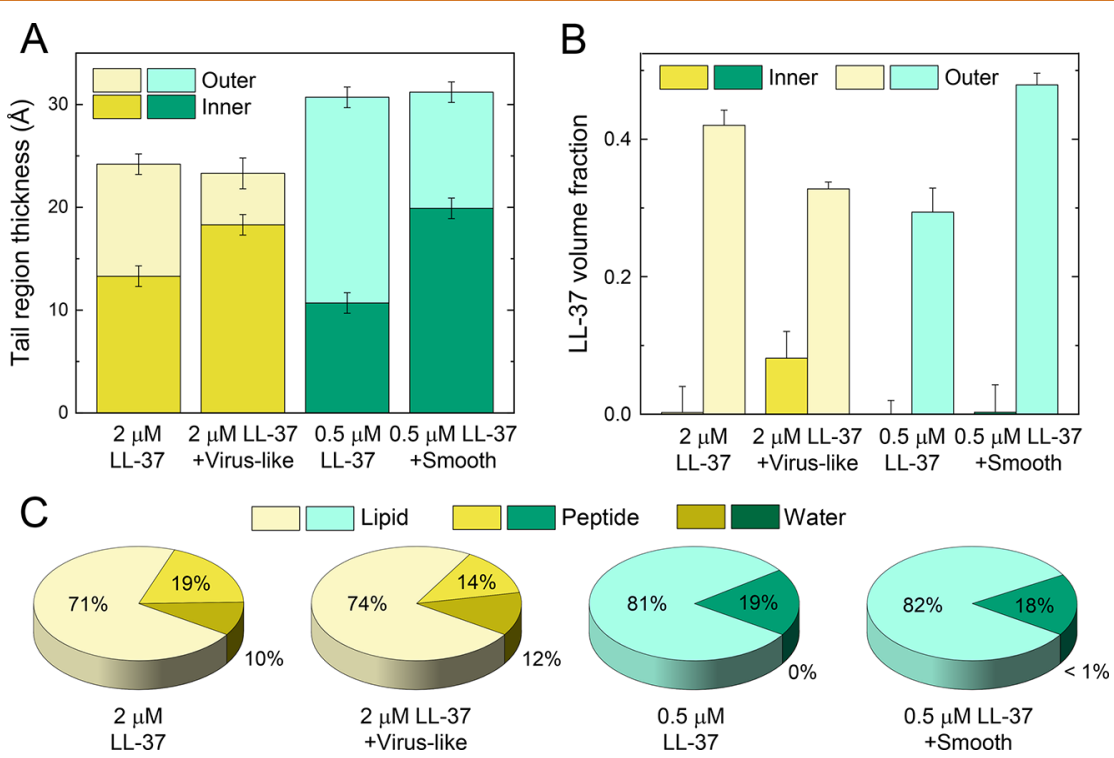

Figure 6. Structural and compositional effects of LL-37 in the absence and presence of virus-like or smooth mesoporous nanoparticles on supported POPC/POPG bilayers obtained from the neutron reflectometry fits. (A) Changes in thickness of the inner and outer tail regions, (B) volume fractions of LL-37 within the two bilayer leaflets, and (C) relative volume fractions of lipid, peptide, and water in the total acyl chain region of the bilayers after incubation with each sample, with calculated errors of $\pm 1 \%$. 


\section{Free peptide}

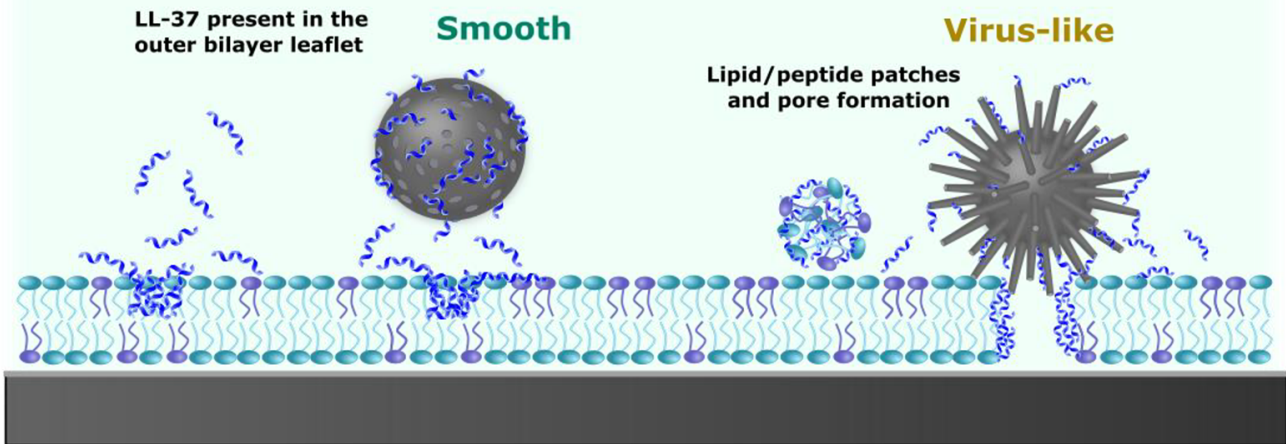

Figure 7. Schematic illustration of the structural effects observed by neutron reflectivity after interaction of POPC/POPG bilayers with virus-like and smooth mesoporous silica nanoparticles loaded with LL-37, as well as with free LL-37. As shown, structural effects induced by the peptide-loaded smooth nanoparticles are modest, and confined to the outer bilayer leaflet. In contrast, LL-37-loaded virus-like nanoparticles induce drastic structural changes, spanning the entire bilayer and being more pronounced than the effects of free LL-37.

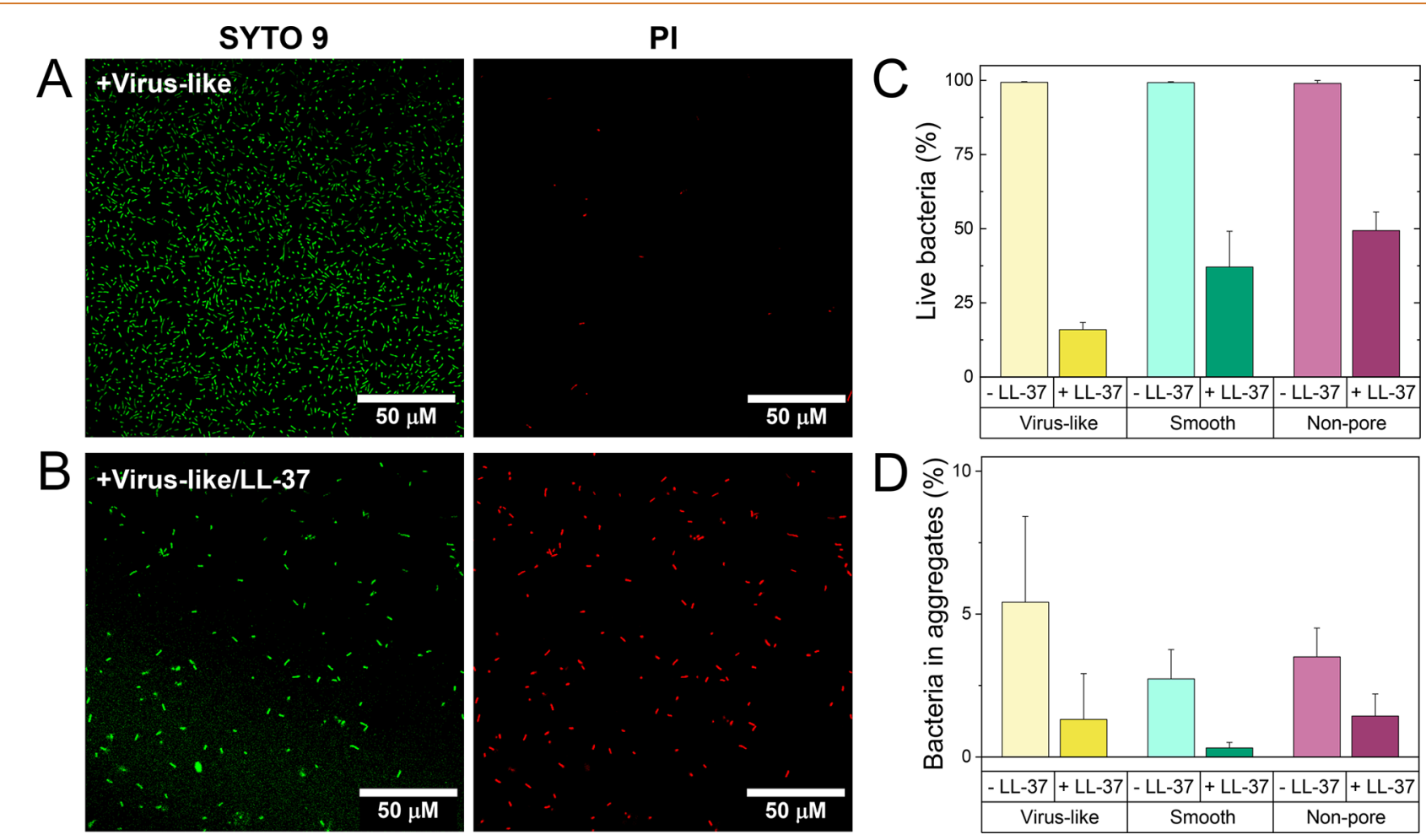

Figure 8. Confocal microscopy result using LIVE/DEAD assay for $10^{8} \mathrm{cfu} / \mathrm{mL}$ of $E$. coli bacteria in $10 \mathrm{mM}$ Tris, pH 7.4, after treatment with $100 \mathrm{ppm}$ nanoparticles with or without LL-37 loading. Representative images for the virus-like nanoparticles obtained by confocal fluorescence microscopy (A, B) using both green (SYTO 9, live + dead) and red (PI, only dead) filter sets. Also results on quantification of the percentages of live bacteria $(C)$ and of bacteria present in aggregates $(D)(n=3$, mean $\pm S D)$.

bilayer thinning was thus obtained, even higher than for free LL-37, with a final thickness of $38 \pm 2 \AA$. Therefore, the results are in line with those obtained for free LL-37 at $2 \mu \mathrm{M}$, but with even more profound bilayer disruption and formation of waterfilled pores. (Note, however, that these former effects are due to the peptide-loaded nanoparticles and not due to free LL-37, as discussed above in relation to Figure 3C). Quantitatively, virus-like nanoparticles loaded with LL-37 at $2 \mu \mathrm{M}$ LL-37 displayed similar levels of material removal $(15 \pm 2 \%$ increase in total bilayer hydration) as those found for free LL-37 at 5 $\mu \mathrm{M}^{22}$ The presence of the extra, highly hydrated lipid-peptide layer necessary to fit the neutron reflectivity profiles was also confirmed in a separate experiment done at lower ionic strength $\left(\mathrm{D}_{2} \mathrm{O} / \mathrm{H}_{2} \mathrm{O}\right)$ (Figure $\mathrm{S} 5$, Tables $\mathrm{S} 3$ and $\mathrm{S} 4$ ). Therefore, these results point to an efficient removal process of the surface-adsorbed material (both lipid bilayer and LL-37, likely also nanoparticles), through peptide-driven defect formation and solubilization of lipid-peptide particles, but only in the simultaneous presence of the virus-like nanoparticles. The results and proposed mode of action are graphically illustrated in Figure 7.

Bacterial Lysis. Bacterial viability assays were finally performed by incubation of Escherichia coli (E. coli) suspensions exposed to the different nanoparticles, either 
bare or loaded with LL-37 to saturation onset ( $5 \mu \mathrm{M}$ for nonporous and smooth mesoporous, $20 \mu \mathrm{M}$ for virus-like mesoporous nanoparticles, all at $100 \mathrm{ppm}$ ). As discussed above in relation to Figure 3C, the effective free LL-37 concentration is very low $(<0.02 \mu \mathrm{M})$ for these samples. Bacterial aliquots were incubated with each of these samples for $30 \mathrm{~min}$ prior to staining with SYTO 9 and propidium iodide (PI) dyes and microscopic visualization. Proper positive (live) and negative (dead, treated with isopropanol) controls were carried out alongside, showing $97.6 \pm 0.4 \%$ and $4.7 \pm 0.1 \%$ of live bacteria, respectively. The bare silica nanoparticles had little effect on the viability of $E$. coli, being close to $100 \%$ live bacteria for the three types (Figure 8). After LL-37 loading onto the nanoparticles, a striking increase in bacterial membrane rupture was observed. Mirroring liposome leakage, ellipsometry, and neutron reflectometry results on model membrane destabilization for the peptide-loaded nanoparticles, such effects were particularly strong for the virus-like nanoparticles (Figure 8B). Quantitatively, the peptide-loaded nanoparticles yielded final percentages of live bacteria of $16 \pm$ $2 \%$ (virus-like), $37 \pm 12 \%$ (smooth mesoporous), and $49 \pm 6 \%$ (nonporous), significantly lower viabilities than for the bare nanoparticles, although higher than for the free peptide $(17 \pm$ $8 \%$ for $5 \mu \mathrm{M}$ and $11 \pm 8 \%$ for $20 \mu \mathrm{M}$ LL-37, respectively) (Figure $8 \mathrm{C}$ ). While the fraction of bacteria in aggregates after exposure to the virus-like nanoparticles is slightly higher than that of the other nanoparticles, the fraction of bacteria in aggregates is modest even in that case (Figure 8D), demonstrating that bacteria lysis occurs without inducing extensive bacterial aggregation. The complete results for these bacterial live/dead assays, including all samples and controls performed, are shown in Figure S6.

Effects of Nanotopography on Membrane Interactions and Disruption. While effects of topography on nanoparticle-membrane interactions have been studied only sparsely before, it is interesting to notice that sharp spikes protruding from macroscopic surfaces have been previously reported to cause membrane damage and bacterial death under gravitational settling. Particularly, Ivanova et al. investigated black silicon, a synthetic nanomaterial that contains highaspect-ratio nanoprotrusions on its surface, comparing this also with high-aspect-ratio nanofeatures on wings of the dragonfly Diplacodes bipunctata (D. bipunctata). ${ }^{28}$ It was shown that the nanoprotrusions on the surfaces of both black silicon and $D$. bipunctata generate a bactericidal effect, independent of chemical composition. Furthermore, such surfaces were demonstrated to be highly bactericidal against both Gramnegative and Gram-positive bacteria, as well as endospores. While the detailed mechanistic origin of these effects was not addressed, they were inferred to be driven by mechanical and structural responses to the deformational stresses imposed by the surface spikes on the peptidoglycan cell wall and inner membrane of bacterial cells. ${ }^{28}$ Extending on this investigation, the same authors addressed the effect of density and height of nanoprotrusions on black silica, and the possible influence on the bactericidal activity of such surfaces against Pseudomonas aeruginosa ( $P$. aeruginosa) and Staphylococcus aureus ( $S$. aureus). The surface with the highest nanoprotrusions and lowest density of tips displayed had the lowest bactericidal effects. Together with findings of effects of architecture on preferential bacterial effect against $P$. aeruginosa and S. aureus, the results suggested that small changes to the surface architecture can affect bactericidal properties of spiky surfaces. ${ }^{37}$ Analogously, Wandiyanto et al. investigated effects of etching on the bactericidal effect of titanium surfaces and found that sharper needle-like structures promote bacterial rupture, ${ }^{38}$ similar to effects seen by graphene nanosheets. ${ }^{39,40}$

Growing spiky features to mesoporous silica nanoparticles, Wang et al. reported on the synthesis of virus-like mesoporous silica nanoparticles of uniform particle size $(80-200 \mathrm{~nm}$ in diameter), also employed in the present investigation. ${ }^{29}$ The particles contained peripheral vertically distributed silica nanotubes with an outside/inside diameter of $10 / 2.5 \mathrm{~nm}$, controllable length $(6-70 \mathrm{~nm})$, and a distance between two adjacent nanotubes of around $30 \mathrm{~nm}$. These virus-like nanoparticles were found to display faster uptake into HeLa cells compared to the nonporous and smooth mesoporous silica nanoparticles. Correspondingly, virus-like nanoparticles loaded with doxorubicin showed much stronger cytotoxic effects compared to smooth mesoporous silica nanoparticles. ${ }^{29}$ Similarly, Song et al. investigated polyethylenimine-modified silica nanoparticles with different morphology and found spiky nanoparticles to display the highest adsorption of plasmid DNA compared to the other two nanoparticles, which in turn resulted in high transfection efficacy. ${ }^{41}$ Thus, the results obtained from the present investigation are in line with promoted membrane interactions and destabilization provided by the presence of spikes at the surface of the virus-like nanoparticles, and extend on these previous findings by (i) providing a mechanistic foundation for these effects, and (ii) demonstrating such topography effects to be amplified in the simultaneous presence of membrane-active antimicrobial peptides.

With regard to structural and composition features involved during membrane interaction and destabilization by mixed nanoparticle/peptide systems, neutron reflectometry offers particularly valuable information. Considering this, it is interesting to compare the results from the present investigation on (LL-37-loaded) silica nanoparticles with previous studies on other types of AMP delivery systems. In the absence of nanoparticles, membrane interactions of LL-37 depend on membrane composition. However, contrary to many other AMPs, membrane interactions by LL-37 are influenced not only by electrostatic but also by hydrophobic interactions. ${ }^{22,42-44}$ With regard to delivery systems for AMPs, Nordström et al. reported on membrane interactions of acrylic acid-based microgels loaded with LL-37 and found these to be qualitatively similar to that of free peptide regarding the following: (i) preferential peptide localization in the acyl chain region of the outer leaflet, (ii) consequences of this for membrane structure, and (iii) insertion occurring by lipid replacement and without defect formation at low peptide concentration but with defect formation at high peptide concentration. ${ }^{22}$ Considering also the very limited membrane binding of microgel particles in the absence of peptide, as well as suppressed kinetics for membrane interaction in the case of microgel-loaded LL-37, these results were inferred to show that membrane interactions for LL-37 preloaded into these microgels occurred through peptide release from the microgels as an intermediate step. ${ }^{22}$ This dependence on peptide release as a necessary intermediate step for membrane interactions and antimicrobial effects is in strong contrast with findings reported by Boge et al. for cubosomes loaded with LL-37. ${ }^{23}$ For the latter system, peptide loading was instead found to result in promoted affinity for the bilayer, in turn resulting in lipid removal and pore formation without peptide release. The 
presently investigated virus-like mesoporous silica nanoparticles represent an intermediate between these two extremes of passive and membrane-active nanoparticles, as effects of nanoparticle topology on both particle attachment and on localized peptide insertion seem to be at play.

The results obtained by neutron reflectivity in the present investigation for the LL-37-loaded virus-like nanoparticles are consistent with the formation of transmembrane water-filled defects $^{43,44}$ and also with previous findings for LL-37 insertion at concentrations around those needed for bacterial killing in vitro. ${ }^{22,45}$ In addition to this, an extra mechanical effect seems to be exerted by the virus-like nanoparticles, but not by the smooth mesoporous ones, likely due to direct action of the spiky nanotubes, which appear to act synergistically with LL-37 in membrane destabilization. One hypothesis of the origin of the "extra mechanical effect" of the virus-like nanoparticles is that the spiky protrusions carry a higher negative surface charge locally on the spike tips, which in turn could increase LL-37 binding to those regions. Such effects of surface topography on local charge densities, with attenuations in "valleys" and enhancements at "peaks", have been recently described and modeled. ${ }^{46}$ The higher negative charge density of spiky protrusions, and the resulting higher electrostatic LL37 binding capacity, could induce membrane puncturing and help inserting peptide molecules deep into the membrane. In addition, the spikes alone induce membrane defects (Figure $3 \mathrm{~A})$, suggesting that local packing defect/dewetting may be induced on nanoparticle binding to the lipid bilayer. On the basis of experimental results from destabilization of bacteria and cell membranes by nanostructured materials, ${ }^{28,37,47}$ theoretical models, and computational simulations, two different models have been proposed for such effects, based either on direct penetration ("impaling") or on surface adhesion and induction of a localized lateral force between the membrane and the spike surface. ${ }^{48}$ In order to generate enough tension and ultimate rupture, either external forces or extremely thin and sharp spikes $(<10 \mathrm{~nm})$ are needed. The breakdown process has been described in the framework of activation energy theory for lipid bilayers, showing that even at low loading forces, a membrane will develop critical, unstable holes when stressed for a sufficient amount of time. ${ }^{49}$

Together, the results presented here point to the formation of solubilized particles or patches on top of the fragmented bilayer. According to our neutron reflectivity results and fits, these appear to be thin $(\sim 5 \mathrm{~nm})$ and relatively scarce $(\sim 90 \%$ total hydration), likely corresponding to lipid or lipid-peptide aggregates. In addition, the presence of virus-like silica nanoparticles cannot be excluded, as such nanoparticles would be totally or partly washed off on rinsing prior to the final characterization with neutrons, also consistent with our ellipsometry data.

\section{CONCLUSIONS}

In the present study, we investigated the effects of nanoparticle topography on membrane interactions of mesoporous silica nanoparticles. For this, virus-like mesoporous nanoparticles (presenting spikes on the external surface) were compared to smooth mesoporous and nonporous silica particles. Although membrane interactions for such bare particles with bacteriamimicking POPC/POPG bilayers were suppressed by repulsive electrostatic interactions, the virus-like particles (but not the smooth ones) displayed membrane destabilization at high particle concentrations. After loading with the antimicrobial peptide LL-37, the effect of nanoparticle topography on membrane destabilization became much more pronounced. Thus, as demonstrated by neutron reflectometry, LL-37-loaded virus-like nanoparticles were more strongly membrane-disruptive than the corresponding peptide-loaded smooth particles, and also more than free LL-37. Membrane destabilization by the peptide-loaded virus-like nanoparticles resulted in large-scale structural and compositional changes. The relevance of these effects for bacterial membrane rupture was further demonstrated by confocal microscopy and live/ dead assays for E. coli bacteria. The results extend on previously reported studies by (i) demonstrating that antimicrobial and membrane-disruptive effects displayed by spiky macroscopic surfaces ${ }^{28}$ translate into spiky nanoparticles; (ii) forming a mechanistic foundation for increased cell internalization observed for virus-like nanoparticles; ${ }^{29}$ and (iii) broadening the parameters demonstrated to affect mesoporous silica nanoparticles as delivery systems for antimicrobial peptides. ${ }^{26}$ They also suggest that virus-like mesoporous nanoparticles could be of interest as delivery systems for antimicrobial peptides.

\section{MATERIALS AND METHODS}

Chemicals. LL-37 (LLGDFFRKSKEKIGKEFKRIVQ RIKDFLRNLVPRTES) was synthesized by Biopeptide Co. (San Diego, CA, USA), and was of $>95 \%$ purity, as evidenced by mass spectral analysis (MALDI-TOF Voyager). 1-Palmitoyl-2-oleoyl-snglycero-3-phosphocholine (POPC; >99\%) and 1-palmitoyl-2-oleoylsn-phosphatidyl-glycerol (POPG; >99\%) were obtained from Avanti Polar Lipids (Alabaster, AL, USA). LIVE/DEAD BacLight Bacterial Viability Kit L7012 was from Thermo Fisher Scientific (Waltham, MA, USA). Ultrapure Milli-Q water $(18.2 \mathrm{M} \Omega \mathrm{cm}$, Millipore) and $\mathrm{D}_{2} \mathrm{O}$ (99\% deuterated, Sigma-Aldrich) were used throughout. All other chemicals used were of analytical grade and obtained from Sigma-Aldrich.

Synthesis of Silica Nanoparticles. Nanoparticles were synthesized following previously established procedures. ${ }^{29}$ In short, solid silica nanoparticles were synthesized using a modified Stöber method. ${ }^{50} \mathrm{~A} 2 \mathrm{~mL}$ aliquot of the silica precursor tetraethyl orthosilicate (TEOS) was added to a mixture of $40 \mathrm{~mL}$ of ethanol, $3 \mathrm{~mL}$ of deionized water, and $0.8 \mathrm{~mL}$ of aqueous ammonia. The solution was stirred for $12 \mathrm{~h}$. For smooth mesoporous nanoparticles, $90 \mathrm{mg}$ of triethanolamine and $1 \mathrm{~g}$ of hexadecyltrimethylammonium bromide (CTAB) were added to $20 \mathrm{~mL}$ of water. The solution was stirred at $60{ }^{\circ} \mathrm{C}$ for $1 \mathrm{~h}$ in a flask. Then, a mixture of $1.5 \mathrm{~mL}$ of TEOS and $6 \mathrm{~mL}$ of cyclohexane was added and kept under stirring for $24 \mathrm{~h}$. Virus-like mesoporous silica nanoparticles were synthesized using an epitaxial growth approach. ${ }^{29}$ In a round-bottom flask, $0.8 \mathrm{~mL}$ of $\mathrm{NaOH}(0.1 \mathrm{M})$ and $1 \mathrm{~g}$ of $\mathrm{CTAB}$ were added to $50 \mathrm{~mL}$ of water and kept under stirring at $60{ }^{\circ} \mathrm{C}$ for $2 \mathrm{~h}$. Subsequently, $20 \mathrm{~mL}$ of TEOS in cyclohexane $(20 \%(\mathrm{v} / \mathrm{v}))$ was added to the solution and stirred at 60 ${ }^{\circ} \mathrm{C}$ for $48 \mathrm{~h}$. All of the nanoparticles above were collected by centrifugation and washed repeatedly with water and ethanol. Both the obtained smooth and virus-like mesoporous nanoparticles were dispersed in acetone and refluxed for $12 \mathrm{~h}$ to remove CTAB templates. Afterward, the samples were washed in ethanol and dried in vacuum at $45^{\circ} \mathrm{C}$ for $8 \mathrm{~h}$.

Transmission Electron Microscopy. TEM images were acquired on a JEM-2100F transmission electron microscope (Jeol, Peabody, USA), employing an accelerating voltage of $200 \mathrm{kV}$ equipped in combination with a postcolumn Gatan imaging filter (GIF-Tridium).

Hydrodynamic Size and $\zeta$-Potential. The hydrodynamic size and $\zeta$-potential of nanoparticles were determined by DLS and $\zeta$ potential measurements performed on a Zeta Plus instrument (Brookhaven Instruments Corp., Holtsville, NY, USA) equipped with a laser operating at $659 \mathrm{~nm}$. The measurements were performed $0,24,48$, and $72 \mathrm{~h}$ after mixing at $100 \mathrm{ppm}$ in $10 \mathrm{mM}$ Tris, $\mathrm{pH}$ 7.4. 
For LL-37-loaded samples, peptide and nanoparticles were equilibrated for $1 \mathrm{~h}$ in $10 \mathrm{mM}$ Tris, $\mathrm{pH} 7.4$, prior to measurements. For DLS, the scattered intensity was collected at $90^{\circ}$ and the hydrodynamic diameter of the particles determined by cumulant fitting stopped at the second order; for $\zeta$-potential, the scattered intensity was collected at $15^{\circ}$ to determine the electrophoretic mobility. The $\zeta$-potential of particles was then calculated using the Helmholtz-Smoluchowski model. All measurements were performed in triplicate at $25^{\circ} \mathrm{C}$.

Liposome Preparation. In preparing unilamellar POPC/POPG liposomes $(75 / 25 \mathrm{~mol} / \mathrm{mol})$, the lipid mixture was dissolved in chloroform and then dried under $\mathrm{N}_{2}$. The film was subsequently placed under vacuum for $10 \mathrm{~h}$ to remove solvent traces, after which lipids were resuspended in $10 \mathrm{mM}$ Tris, $\mathrm{pH} 7.4$, to obtain multilamellar suspensions. Following this, samples were exposed to 8 freeze-thaw cycles, followed by different homogenization procedures depending on the specific technique by which they were subsequently used in order to obtain unilamellar suspensions.

Liposome Leakage Assay. POPC/POPG liposomes were also prepared in $10 \mathrm{mM}$ Tris, $\mathrm{pH} 7.4$, as described above, but in the presence of $100 \mathrm{mM}$ of the fluorescent dye carboxyfluorescein (CF), and homogenized by extrusion 31 times through a $100 \mathrm{~nm}$ filter using a LipoFast miniextruder (Avestin, Ottawa, Canada). ${ }^{51}$ Nonencapsulated dye was removed by gel filtration (Sephadex G-50, GE Healthcare, Uppsala, Sweden). Liposome leakage was followed by adding nanoparticle and AMP aliquots to $10 \mu \mathrm{M}$ liposome suspensions in $10 \mathrm{mM}$ Tris, $\mathrm{pH} 7.4$, and recording the CF fluorescent emission at $520 \mathrm{~nm}$ using a Cary Eclipse fluorescence spectrophotometer (Agilent Technologies, Santa Clara, CA, USA) at $25{ }^{\circ} \mathrm{C}$ for $30 \mathrm{~min}$. At the end of each experiment, liposomes were completely disrupted by addition of $0.8 \mathrm{mM}$ Triton X-100 for absolute quantification. Measurements were performed in triplicate.

Ellipsometry. Using an Optrel Multiskop (Optrel, Kleinmachnow, Germany), nanoparticle binding to supported lipid bilayers was studied in situ by null ellipsometry. ${ }^{52,53}$ Measurements were performed at $532 \mathrm{~nm}$ and with an angle of incidence of $67.66^{\circ}$ in a $5 \mathrm{~mL}$ cuvette under stirring (300 $\mathrm{rpm})$. Silica substrates were prepared from polished silicon wafers, oxidized to an oxide layer thickness of $30 \mathrm{~nm}$ (Semiconductor Wafer Inc., Hsinchu, Taiwan). The resulting silica substrates were cleaned, first in $25 \% \mathrm{NH}_{4} \mathrm{OH}, 30 \%$ $\mathrm{H}_{2} \mathrm{O}_{2}$, and $\mathrm{H}_{2} \mathrm{O}\left(1 / 1 / 5\right.$ by mass), and then in $25 \% \mathrm{HCl}, 30 \% \mathrm{H}_{2} \mathrm{O}_{2}$, and $\mathrm{H}_{2} \mathrm{O}(1 / 1 / 5$ by mass $)$, both at $80{ }^{\circ} \mathrm{C}$ for $5 \mathrm{~min}$. The surfaces were rinsed thoroughly in water and ethanol (99.7\%). This resulted in negatively charged $(z=-40 \mathrm{mV})$ and highly hydrophilic $\left(\theta<10^{\circ}\right)$ surfaces. ${ }^{54}$

Supported lipid bilayers were prepared by liposome fusion onto these surfaces. POPC/POPG $(75 / 25(\mathrm{~mol} / \mathrm{mol}))$ liposomes were prepared as described above in $10 \mathrm{mM}$ Tris, $\mathrm{pH} 7.4$ buffer and extruded 31 times through a $100 \mathrm{~nm}$ filter and further 31 times through a $30 \mathrm{~nm}$ filter using a LipoFast miniextruder (Avestin). ${ }^{51}$ Before lipid addition, surfaces were precoated by adsorption of poly-Llysine at low ionic strength to obtain a flat net positively charged surface, which has been previously demonstrated to efficiently suppress peptide adsorption to the underlying silica surface through any defects in the supported lipid bilayer. ${ }^{51}$ After this, the cuvette solution was changed to $2 \mathrm{mM} \mathrm{CaCl}$ before liposome addition (20 $\mu \mathrm{M})$ to facilitate liposome deposition. Once stabilized, the cuvette was rinsed with $10 \mathrm{mM}$ Tris, $\mathrm{pH}$ 7.4, for $15 \mathrm{~min}$. The resulting layer had structural characteristics that indicated an adsorbed bilayer with close to full coverage (thickness $=4 \pm 1 \mathrm{~nm}$; mean refractive index $=$ $1.47 \pm 0.03$ ). Nanoparticles were added to a concentration of 100 ppm either alone or after preloading with LL-37 to saturation concentration. All measurements were performed in duplicate at 25 ${ }^{\circ} \mathrm{C}$.

Neutron Reflectometry. To investigate changes in the bilayer structure on exposure to peptide and nanoparticles, neutron reflectometry experiments were performed using the horizontal reflectometer INTER at the ISIS Pulsed Neutron and Muon Source (Rutherford Appleton Laboratory, Harwell, U.K.). ${ }^{55}$ Two incident angles, $0.7^{\circ}$ and $2.3^{\circ}$, were used to measure the whole $Q$-range of interest $\left(0.01-0.33 \AA^{-1}\right)$. Solid-liquid interface cells were used, which were kept at $37^{\circ} \mathrm{C}$ using a circulating water bath. Bare silicon (111) surfaces $(80 \mathrm{~mm} \times 50 \mathrm{~mm} \times 15 \mathrm{~mm}$, one face polished, RMS < $4.5 \AA$, Sil'tronix, France) were characterized in $\mathrm{D}_{2} \mathrm{O}$ and $\mathrm{H}_{2} \mathrm{O}$. The surfaces were pre-incubated with $2 \mathrm{mM} \mathrm{CaCl}_{2}$ solution prior to liposome injection. POPC/POPG liposomes $(0.1 \mathrm{mg} / \mathrm{mL})$ were subsequently mixed with $2 \mathrm{mM} \mathrm{CaCl}$ and injected in the cells. After 20 min of incubation to allow for liposome deposition, the excess was rinsed off with $10 \mathrm{mM}$ dTris, $\mathrm{pH} 7.4$, and the bilayers were characterized in 3 contrasts: Tris buffer in $\mathrm{D}_{2} \mathrm{O}$ (dTris), Tris buffer in $\mathrm{H}_{2} \mathrm{O}$ (hTris), and Tris buffer in a $\mathrm{D}_{2} \mathrm{O} / \mathrm{H}_{2} \mathrm{O}$ mixture contrastmatching the silicon surface, i.e., with the same scattering length density (SLD $=2.07 \times 10^{-6} \AA^{-2}$, CMTris) (all buffers at $10 \mathrm{mM}, \mathrm{pH}$ 7.4). After bilayer characterization, $10 \mathrm{ppm}$ of nanoparticles (either alone or after loading with LL-37) were injected into the cells. Corresponding concentrations of free LL-37 were used as controls. In all cases, samples were left to incubate for $30 \mathrm{~min}$ before rinsing off with $20 \mathrm{~mL}$ of dTris, followed by final characterization in 3 contrasts (dTris, hTris, CMTris).

The neutron reflectivity curves obtained were analyzed using SLD data for the different components (Table S1), used as input for the RasCAL reflectivity fitting software, containing algorithms based on Parratt formulation. ${ }^{56}$ The reflectivity profiles obtained for the bare silicon surfaces in hTris and dTris were fitted first and their surface roughness, $\mathrm{SiO}_{2}$ layer thickness, and hydration values then used to fit the neutron reflectivity data of the deposited bilayers. The different contrasts employed to characterize each bilayer were fitted simultaneously. This was done for the bilayers before and after incubation with the different samples. Fitting errors were estimated using RasCAL's Bootstrap algorithm, for which random initial values were used for the different model parameters, and the resulting error distribution was used to calculate error propagation. ${ }^{57}$

Live/Dead Bacterial Viability Assay. In order to investigate effects of virus-like and smooth mesoporous nanoparticles in the absence or presence of LL-37, bacterial cultures of E. coli ATCC 25922 were exposed to these samples and stained using the LIVE/ DEAD BacLight Bacterial Viability Kit (L7012, Thermo Fisher Scientific). Bacteria were grown to stationary phase in $5 \mathrm{~mL}$ of $\mathrm{LB}$ medium at $37^{\circ} \mathrm{C}$, shaking at $180 \mathrm{rpm}$ at room temperature overnight. The culture medium was washed away twice by centrifugation in 10 $\mathrm{mM}$ Tris buffer, $\mathrm{pH} 7.4(10000 \mathrm{~g}, 10 \mathrm{~min})$, and the pellet, resuspended in $5 \mathrm{~mL}$ of Tris buffer. This volume was subsequently adjusted to obtain an optical density $\mathrm{OD}_{600}=0.6$, which corresponds to the order of $10^{8}$ colony forming units $(\mathrm{cfu}) / \mathrm{mL}$ (confirmed on subsequent dilution, plating, culture, and counting of colonies). Nanoparticle dispersions at $100 \mathrm{ppm}$, either bare or loaded with LL-37 at their maximum loading capacity ( $5 \mu \mathrm{M}$ for nonporous and smooth mesoporous; $20 \mu \mathrm{M}$ for virus-like mesoporous nanoparticles), were prepared as described above in $10 \mathrm{mM}$ Tris buffer, $\mathrm{pH}$ 7.4. The effect of the free peptide at both concentrations was also tested. In addition, positive (live) and negative (dead) controls were included by (i) no treatment and (ii) treatment with isopropanol during the centrifugation steps, respectively. Samples were added to the bacterial suspension ( $200 \mu \mathrm{L}$ final volume) and incubated for $30 \mathrm{~min}$ at room temperature. This was followed by staining for $15 \mathrm{~min}$ with a $1 / 1$ (v/ v) dilution of the two fluorescent probes SYTO 9 (which labels the nuclei of both live and dead cells) and PI (which labels only dead or membrane-compromised cells). ${ }^{58}$ Subsequently, samples were visualized with a LSM 710 Axio Imager 2 confocal microscope (ZEISS, Oberkochen, Germany) using the green/EGFP (488 nm excitation, $526 \mathrm{~nm}$ emission) and red/PI (543 nm excitation, $652 \mathrm{~nm}$ emission) filter sets. For each control and sample preparation, 10 randomized, wide-field images $(200 \mu \mathrm{m} \times 200 \mu \mathrm{m})$ were collected. Image analysis was carried out using Image $J^{59}$ to calculate the relative area occupied by the green minus the red fluorescent signal with respect to the green signal (as percentage of live bacteria) and to quantify the number of bacteria aggregates with respect to total bacteria. The assays were run in triplicate at $25{ }^{\circ} \mathrm{C}$. 


\section{ASSOCIATED CONTENT}

\section{S1 Supporting Information}

The Supporting Information is available free of charge at https://pubs.acs.org/doi/10.1021/acsnano.0c10378.

Summaries of input parameters, neutron reflectivity curves and best fits, together with full structural data obtained from the fits and schematic illustrations of the different models considered; additional DLS results; and full quantification of the live/dead bacteria assays (PDF)

\section{AUTHOR INFORMATION}

\section{Corresponding Author}

Elisa Parra-Ortiz - Department of Pharmacy, University of Copenhagen, DK-2100 Copenhagen, Denmark; 이이.org/ 0000-0003-2219-8866; Phone: +4535328251;

Email: elisa.parra@sund.ku.dk

\section{Authors}

Sara Malekkhaiat Häffner - Department of Pharmacy, University of Copenhagen, DK-2100 Copenhagen, Denmark; (1) orcid.org/0000-0003-4111-8075

Kathryn L. Browning - Department of Pharmacy, University of Copenhagen, DK-2100 Copenhagen, Denmark

Elin Jørgensen - Costerton Biofilm Center, Department of Immunology and Microbiology, University of Copenhagen, DK-2200 Copenhagen, Denmark

Maximilian W. A. Skoda - ISIS Pulsed Neutron and Muon Source, Rutherford Appleton Laboratory, Harwell, Oxfordshire OX11 OQX, United Kingdom

Costanza Montis - CSGI and Department of Chemistry "Ugo Schiff", University of Florence, IT-50019 Sesto Fiorentino, Italy; orcid.org/0000-0001-6960-3772

Xiaomin Li - Department of Chemistry, Collaborative Innovation Center of Chemistry for Energy Materials, State Key Laboratory of Molecular Engineering of Polymers, Fudan University, Shanghai 200433, People's Republic of China; (1) orcid.org/0000-0001-6056-6928

Debora Berti - CSGI and Department of Chemistry "Ugo Schiff", University of Florence, IT-50019 Sesto Fiorentino, Italy; io orcid.org/0000-0001-8967-560X

Dongyuan Zhao - Department of Chemistry, Collaborative Innovation Center of Chemistry for Energy Materials, State Key Laboratory of Molecular Engineering of Polymers, Fudan University, Shanghai 200433, People's Republic of China; (1) orcid.org/0000-0001-8440-6902

Martin Malmsten - Department of Pharmacy, University of Copenhagen, DK-2100 Copenhagen, Denmark; Department of Physical Chemistry 1, University of Lund, SE-22100 Lund, Sweden

Complete contact information is available at:

https://pubs.acs.org/10.1021/acsnano.0c10378

\section{Author Contributions}

S.M.H., E.P.-O., K.L.B., and M.M. designed the study. M.M. secured funding. All authors were involved in the performance of the experiments and the interpretation of the experimental results. S.M.H., E.P.-O., and M.M. wrote the manuscript with contributions from all authors. All authors gave their approval to the final manuscript version.

Notes

The authors declare no competing financial interest.

\section{ACKNOWLEDGMENTS}

We acknowledge the support from ISIS Pulsed Neutron and Muon Source, Rutherford Appleton Laboratory, for the awarded neutron beam time (experiment RB1920384, DOI: 10.5286/ISIS.E.RB1920384), and support from the Swedish Research Council (Project 2016-05157; M.M.), the Independent Research Fund Denmark (Project 9040-00020B; M.M. and E.P.-O.), and the LEO Foundation Center for Cutaneous Drug Delivery (Project 2016-11-01; M.M., K.L.B., and E.J.). Liv Sofia Elinor Davies is gratefully acknowledged for experimental support during the neutron reflectometry experiments. We are also grateful to Dr. Luke Clifton, Rutherford Appleton Laboratory, for technical support at the ISIS Pulsed Neutron and Muon Source.

\section{REFERENCES}

(1) Centers for Disease Control and Prevention (CDC). Antibiotic Resistance Threats in the United States; CDC, U.S. Department of Health and Human Services: Atlanta, GA, USA, 2019; DOI: $10.15620 / \mathrm{cdc}: 82532$.

(2) Hancock, R. E. W.; Haney, E. F.; Gill, E. E. The Immunology of Host Defence Peptides: Beyond Antimicrobial Activity. Nat. Rev. Immunol. 2016, 16, 321-334.

(3) Pasupuleti, M.; Schmidtchen, A.; Malmsten, M. Antimicrobial Peptides: Key Components of the Innate Immune System. Crit. Rev. Biotechnol. 2012, 32 (2), 143-171.

(4) Cardoso, M. H.; Orozco, R. Q.; Rezende, S. B.; Rodrigues, G.; Oshiro, K. G.; Cândido, E. S.; Franco, O. L. Computer-Aided Design of Antimicrobial Peptides: Are We Generating Effective Drug Candidates? Front. Microbiol. 2020, 10, 3097.

(5) Malmsten, M.; Kasetty, G.; Pasupuleti, M.; Alenfall, J.; Schmidtchen, A. Highly Selective End-Tagged Antimicrobial Peptides Derived from PRELP. PLoS One 2011, 6 (1), No. e16400.

(6) Malmsten, M.; Davoudi, M.; Walse, B.; Rydengard, V.; Pasupuleti, M.; Morgelin, M.; Schmidtchen, A. Antimicrobial Peptides Derived from Growth Factors. Growth Factors 2007, 25 (1), 60-70.

(7) Nordström, R.; Malmsten, M. Delivery Systems for Antimicrobial Peptides. Adv. Colloid Interface Sci. 2017, 242, 17-34.

(8) Malmsten, M. Inorganic Nanomaterials as Delivery Systems for Proteins, Peptides, DNA, and siRNA. Curr. Opin. Colloid Interface Sci. 2013, 18 (5), 468-480.

(9) Malekkhaiat Häffner, S.; Malmsten, M. Membrane Interactions and Antimicrobial Effects of Inorganic Nanoparticles. Adv. Colloid Interface Sci. 2017, 248, 105-128.

(10) Huh, A. J.; Kwon, Y. J. "Nanoantibiotics": A New Paradigm for Treating Infectious Diseases Using Nanomaterials in the Antibiotics Resistant Era. J. J. Controlled Release 2011, 156 (2), 128-145.

(11) Malekkhaiat Häffner, S.; Nyström, L.; Nordström, R.; Xu, Z. P.; Davoudi, M.; Schmidtchen, A.; Malmsten, M. Membrane Interactions and Antimicrobial Effects of Layered Double Hydroxide Nanoparticles. Phys. Chem. Chem. Phys. 2017, 19 (35), 23832-23842.

(12) Huang, L.; Terakawa, M.; Zhiyentayev, T.; Huang, Y.-Y.; Sawayama, Y.; Jahnke, A.; Tegos, G. P.; Wharton, T.; Hamblin, M. R. Innovative Cationic Fullerenes as Broad-Spectrum Light-Activated Antimicrobials. Nanomedicine 2010, 6 (3), 442-452.

(13) Arora, B.; Murar, M.; Dhumale, V. Antimicrobial Potential of TiO2 Nanoparticles against MDR Pseudomonas aeruginosa. J. Exp. Nanosci. 2015, 10 (11), 819-827.

(14) Erdem, A.; Metzler, D.; Cha, D. K.; Huang, C. P. The ShortTerm Toxic Effects of TiO(2)Nanoparticles toward Bacteria through Viability, Cellular Respiration, and Lipid Peroxidation. Environ. Sci. Pollut. Res. 2015, 22 (22), 17917-24.

(15) Nguyen, T. K.; Duong, H. T.; Selvanayagam, R.; Boyer, C.; Barraud, N. Iron Oxide Nanoparticle-Mediated Hyperthermia Stimulates Dispersal in Bacterial Biofilms and Enhances Antibiotic Efficacy. Sci. Rep. 2015, 5, 18385. 
(16) Zhu, K.; Ju, Y.; Xu, J.; Yang, Z.; Gao, S.; Hou, Y. Magnetic Nanomaterials: Chemical Design, Synthesis, and Potential Applications. Acc. Chem. Res. 2018, 51 (2), 404-413.

(17) Yin, W.; Yu, J.; Lv, F.; Yan, L.; Zheng, L. R.; Gu, Z.; Zhao, Y. Functionalized Nano-MoS2 with Peroxidase Catalytic and NearInfrared Photothermal Activities for Safe and Synergetic Wound Antibacterial Applications. ACS Nano 2016, 10 (12), 11000-11011. (18) Chen, Y.; Gao, Y.; Chen, Y.; Liu, L.; Mo, A.; Peng, Q. Nanomaterials-Based Photothermal Therapy and Its Potentials in Antibacterial Treatment. I. Controlled Release 2020, 328, 251-262.

(19) Malekkhaiat Häffner, S.; Malmsten, M. Interplay between Amphiphilic Peptides and Nanoparticles for Selective Membrane Destabilization and Antimicrobial Effects. Curr. Opin. Colloid Interface Sci. 2019, 44, 59-71.

(20) Veronese, F. M.; Mero, A. The Impact of PEGylation on Biological Therapies. BioDrugs 2008, 22 (5), 315-329.

(21) Singh, S.; Papareddy, P.; Morgelin, M.; Schmidtchen, A.; Malmsten, M. Effects of PEGylation on Membrane and Mipopolysaccharide Interactions of Host Defense Peptides. Biomacromolecules 2014, 15 (4), 1337-1345.

(22) Nordström, R.; Browning, K. L.; Parra-Ortiz, E.; Damgaard, L. S. E.; Häffner, S. M.; Maestro, A.; Campbell, R. A.; Cooper, J. F. K.; Malmsten, M. Membrane Interactions of Antimicrobial PeptideLoaded Microgels. J. Colloid Interface Sci. 2020, 562, 322-332.

(23) Boge, L.; Browning, K. L.; Nordström, R.; Campana, M.; Damgaard, L. S. E.; Seth Caous, J.; Hellsing, M.; Ringstad, L.; Andersson, M. Peptide-Loaded Cubosomes Functioning as an Antimicrobial Unit against Escherichia coli. ACS Appl. Mater. Interfaces 2019, 11 (24), 21314-21322.

(24) Manzano, M.; Vallet-Regí, M. Mesoporous Silica Nanoparticles for Drug Delivery. Adv. Funct. Mater. 2020, 30 (2), 1902634.

(25) Flynn, J.; Mallen, S.; Durack, E.; O'Connor, P. M.; Hudson, S. P. Mesoporous Matrices for the Delivery of the Broad Spectrum Bacteriocin. J. Colloid Interface Sci. 2019, 537, 396-406.

(26) Braun, K.; Pochert, A.; Linden, M.; Davoudi, M.; Schmidtchen, A.; Nordstrom, R.; Malmsten, M. Membrane Interactions of Mesoporous Silica Nanoparticles as Carriers of Antimicrobial Peptides. J. Colloid Interface Sci. 2016, 475, 161-170.

(27) Gelderblom, H. R. Structure and Classification of Viruses. In Medical Microbiology, 4th ed.; Baron, S., Ed.; University of Texas Medical Branch at Galveston: Galveston, TX, USA, 1996; Chapter 41.

(28) Ivanova, E. P.; Hasan, J.; Webb, H. K.; Gervinskas, G.; Juodkazis, S.; Truong, V. K.; Wu, A. H. F.; Lamb, R. N.; Baulin, V. A.; Watson, G. S.; Watson, J. A.; Mainwaring, D. E.; Crawford, R. J. Bactericidal Activity of Black Silicon. Nat. Commun. 2013, 4 (1), 2838.

(29) Wang, W.; Wang, P.; Tang, X.; Elzatahry, A. A.; Wang, S.; AlDahyan, D.; Zhao, M.; Yao, C.; Hung, C.-T.; Zhu, X.; Zhao, T.; Li, X.; Zhang, F.; Zhao, D. Facile Synthesis of Uniform Virus-Like Mesoporous Silica Nanoparticles for Enhanced Cellular Internalization. ACS Cent. Sci. 2017, 3 (8), 839-846.

(30) Kaasalainen, M.; Aseyev, V.; von Haartman, E.; Karaman, D. Ş.; Mäkilä, E.; Tenhu, H.; Rosenholm, J.; Salonen, J. Size, Stability, and Porosity of Mesoporous Nanoparticles Characterized with Light Scattering. Nanoscale Res. Lett. 2017, 12 (1), 74.

(31) Browning, K. L.; Lind, T. K.; Maric, S.; Malekkhaiat-Häffner, S.; Fredrikson, G. N.; Bengtsson, E.; Malmsten, M.; Cárdenas, M. Human Lipoproteins at Model Cell Membranes: Effect of Lipoprotein Class on Lipid Exchange. Sci. Rep. 2017, 7 (1), 7478.

(32) Kučerka, N.; Tristram-Nagle, S.; Nagle, J. F. Structure of Fully Hydrated Fluid Phase Lipid Bilayers with Monounsaturated Chains. J. Membr. Biol. 2006, 208 (3), 193-202.

(33) Pabst, G.; Danner, S.; Karmakar, S.; Deutsch, G.; Raghunathan, V. A. On the Propensity of Phosphatidylglycerols to Form Interdigitated Phases. Biophys. J. 2007, 93 (2), 513-525.

(34) Koenig, B. W.; Gawrisch, K. Specific Volumes of Unsaturated Phosphatidylcholines in the Liquid Crystalline Lamellar Phase. Biochim. Biophys. Biochim. Biophys. Acta, Biomembr. 2005, 1715 (1), $65-70$.
(35) Pan, J.; Heberle, F. A.; Tristram-Nagle, S.; Szymanski, M.; Koepfinger, M.; Katsaras, J.; Kučerka, N. Molecular Structures of Fluid Phase Phosphatidylglycerol Bilayers as Determined by Small Angle Neutron and X-Ray Scattering. Biochim. Biophys. Acta, Biomembr. 2012, 1818 (9), 2135-2148.

(36) Kučerka, N.; Nieh, M.-P.; Katsaras, J. Fluid Phase Lipid Areas and Bilayer Thicknesses of Commonly Used Phosphatidylcholines as a Function of Temperature. Biochim. Biophys. Acta, Biomembr. 2011, 1808 (11), 2761-2771.

(37) Bhadra, C. M.; Werner, M.; Baulin, V. A.; Truong, V. K.; Kobaisi, M. A.; Nguyen, S. H.; Balcytis, A.; Juodkazis, S.; Wang, J. Y.; Mainwaring, D. E.; Crawford, R. J.; Ivanova, E. P. Subtle Variations in Surface Properties of Black Silicon Surfaces Influence the Degree of Bactericidal Efficiency. Nano-Micro Lett. 2018, 10 (2), 36.

(38) Wandiyanto, J. V.; Tamanna, T.; Linklater, D. P.; Truong, V. K.; Al Kobaisi, M.; Baulin, V. A.; Joudkazis, S.; Thissen, H.; Crawford, R. J.; Ivanova, E. P. Tunable Morphological Changes of Asymmetric Titanium Nanosheets with Bactericidal Properties. J. Colloid Interface Sci. 2020, 560, 572-580.

(39) Pham, V. T. H.; Truong, V. K.; Quinn, M. D. J.; Notley, S. M.; Guo, Y.; Baulin, V. A.; Al Kobaisi, M.; Crawford, R. J.; Ivanova, E. P. Graphene Induces Formation of Pores that Kill Spherical and RodShaped Bacteria. ACS Nano 2015, 9 (8), 8458-8467.

(40) Li, Y.; Yuan, H.; von dem Bussche, A.; Creighton, M.; Hurt, R. H.; Kane, A. B.; Gao, H. Graphene Microsheets Enter Cells through Spontaneous Membrane Penetration at Edge Asperities and Corner Sites. Proc. Natl. Acad. Sci. U. S. A. 2013, 110 (30), 12295-12300.

(41) Song, H.; Yu, M.; Lu, Y.; Gu, Z.; Yang, Y.; Zhang, M.; Fu, J.; Yu, C. Plasmid DNA Delivery: Nanotopography Matters. J. Am. Chem. Soc. 2017, 139 (50), 18247-18254.

(42) Lee, C. C.; Sun, Y.; Qian, S.; Huang, H. W. Transmembrane Pores Formed by Human Antimicrobial Peptide LL-37. Biophys. $J$ 2011, 100 (7), 1688-96.

(43) Henzler Wildman, K. A.; Lee, D.-K.; Ramamoorthy, A. Mechanism of Lipid Bilayer Disruption by the Human Antimicrobial Peptide, LL-37. Biochemistry 2003, 42 (21), 6545-6558.

(44) Henzler-Wildman, K. A.; Martinez, G. V.; Brown, M. F.; Ramamoorthy, A. Perturbation of the Hydrophobic Core of Lipid Bilayers by the Human Antimicrobial Peptide LL-37. Biochemistry 2004, 43 (26), 8459-69.

(45) Nordström, R.; Nyström, L.; Andren, O. C. J.; Malkoch, M.; Umerska, A.; Davoudi, M.; Schmidtchen, A.; Malmsten, M. Membrane Interactions of Microgels as Carriers of Antimicrobial Peptides. J. Colloid Interface Sci. 2018, 513, 141-150.

(46) Alan, B. O.; Barisik, M.; Ozcelik, H. G. Roughness Effects on the Surface Charge Properties of Silica Nanoparticles. J. Phys. Chem. C 2020, 124 (13), 7274-7286.

(47) Linklater, D. P.; Baulin, V. A.; Juodkazis, S.; Crawford, R. J.; Stoodley, P.; Ivanova, E. P. Mechano-Bactericidal Actions of Nanostructured Surfaces. Nat. Rev. Microbiol. 2021, 19 (1), 8-22.

(48) Xie, X.; Xu, A. M.; Angle, M. R.; Tayebi, N.; Verma, P.; Melosh, N. A. Mechanical Model of Vertical Nanowire Cell Penetration. Nano Lett. 2013, 13 (12), 6002-6008.

(49) Evans, E.; Smith, B. A. Kinetics of Hole Nucleation in Biomembrane Rupture. New J. Phys. 2011, 13 (9), 095010.

(50) Stöber, W.; Fink, A.; Bohn, E. Controlled Growth of Monodisperse Silica Spheres in the Micron Size Range. J. Colloid Interface Sci. 1968, 26 (1), 62-69.

(51) Ringstad, L.; Schmidtchen, A.; Malmsten, M. Effect of Peptide Length on the Interaction between Consensus Peptides and DOPC/ DOPA Bilayers. Langmuir 2006, 22 (11), 5042-5050.

(52) Azzam, R. M. A.; Bashara, N. M.; Ballard, S. S. Ellipsometry and Polarized Light. Phys. Today 1978, 31 (11), 72.

(53) Malmsten, M. Ellipsometry Studies of Protein Layers Adsorbed at Hydrophobic Surfaces. J. Colloid Interface Sci. 1994, 166 (2), 333342.

(54) Malmsten, M.; Burns, N.; Veide, A. Electrostatic and Hydrophobic Effects of Oligopeptide Insertions on Protein Adsorption. J. Colloid Interface Sci. 1998, 204 (1), 104-11. 
(55) Webster, J.; Holt, S.; Dalgliesh, R. INTER the Chemical Interfaces Reflectometer on Target Station 2 at ISIS. Phys. B 2006, 385, 1164-1166.

(56) Parratt, L. G. Surface Studies of Solids by Total Reflection of XRays. Phys. Rev. 1954, 95 (2), 359-369.

(57) Efron, B. Bootstrap Methods: Another Look at the Jackknife. In Breakthroughs in Statistics: Methodology and Distribution; Kotz, S., Johnson, N. L., Eds.; Springer: New York, NY, USA, 1992; pp 569593, DOI: 10.1007/978-1-4612-4380-9.

(58) Boulos, L.; Prevost, M.; Barbeau, B.; Coallier, J.; Desjardins, R. LIVE/DEAD ${ }^{\circledR}$ BacLight: Application of a New Rapid Staining Method for Direct Enumeration of Viable and Total Bacteria in Drinking Water. J. Microbiol. Methods 1999, 37 (1), 77-86.

(59) Schneider, C. A.; Rasband, W. S.; Eliceiri, K. W. NIH Image to ImageJ: 25 Years of Image Analysis. Nat. Methods 2012, 9 (7), 671675. 